\title{
Ground-State Proton-Transfer (GSPT)-Assisted Enhanced Two- Photon Uncaging from a Binol-based AIE-Fluorogenic Phototrigger
}

\author{
Biswajit Roy, ${ }^{\text {a Samrat Roy, }}{ }^{\mathrm{b}}$ Moumita Kundu, ${ }^{\mathrm{c}}$ Somnath Maji, ${ }^{\mathrm{d}}$ Bipul Pal, ${ }^{\mathrm{b}}$ Mahitosh Mandal, ${ }^{\mathrm{c}}$ \\ N. D. Pradeep Singh ${ }^{\mathrm{a}^{*}}$ \\ aDepartment of Chemistry, Indian Institute of Technology Kharagpur, Kharagpur-721302, India. \\ ${ }^{b}$ Department of Physics, Indian Institute of Science Education and Research Kolkata, Mohanpur, \\ West Bengal 741246, India.
}

'School of Medical Science and Technology, Indian Institute of Technology Kharagpur, Kharagpur-721302, India.

dDepartment of Biotechnology, Indian Institute of Technology Kharagpur, Kharagpur-721302, India.

\section{Supporting Information}


Table of Contents

\begin{tabular}{|c|c|}
\hline Contents & Page Number \\
\hline 1. General experimental details & S4 \\
\hline 2.Synthesis of Binol-VPA, Binol-VPA and Binol-OMe-VPA & S5 \\
\hline 3. Experimental procedure and Spectroscopic data & S6-S8 \\
\hline 4. ${ }^{1} \mathrm{H}$ and ${ }^{13} \mathrm{C}$ NMR Spectra & S9-S13 \\
\hline 5. RP-HPLC profile of Binol-VPA, Binol-VPA and Binol-OMe-VPA & S-14 \\
\hline 6. Photophysical properties & S14-S19 \\
\hline 6.1. Absorption and emission spectra of Binol-VPA: & S14 \\
\hline 6.2. Absorption and emission spectra of Binol-Cbl & S15 \\
\hline $\begin{array}{l}\text { 6.3. Absorption and emission spectra of Binol-VPA with different } \\
\text { pH and dilute } \mathrm{NaOH} \text { solution }\end{array}$ & S16 \\
\hline $\begin{array}{l}\text { 6.4. Absorption and emission spectra of Binol-VPA with } \mathrm{NaOH} \\
\text { solution of different concentration }\end{array}$ & S17 \\
\hline $\begin{array}{l}\text { 6.5. Absorption and emission spectra of Binol-VPA-OMe with } \\
\text { different } \mathrm{pH} \text { : }\end{array}$ & S18 \\
\hline $\begin{array}{l}\text { 6.6. Absorption and emission spectra of Binol-VPA with DMSO } \\
\text { buffer mixture with different } f_{w}\end{array}$ & S19 \\
\hline 7. Z-scan measurement: & S20-S21 \\
\hline $\begin{array}{l}\text { 7.1. TPA cross-section of Binol-VPA and Binol-Cbl at different } \\
\text { wavelengths Binol-Cbl }\end{array}$ & S22 - S24 \\
\hline $\begin{array}{l}\text { 7.2. TPA cross-section at different water fraction for Binol-VPA } \\
\text { andBinol-Cbl }\end{array}$ & S25 - S27 \\
\hline 8. Stability of prodrugs: & S28 \\
\hline
\end{tabular}




\begin{tabular}{|c|c|}
\hline $\begin{array}{l}\text { 9. Procedure for the quantification of the released drug from Binol- } \\
\text { Cbl and Binol-VPA: }\end{array}$ & S29-S36 \\
\hline 10.meassurement of the emission spectra durring the photorelease & S37 \\
\hline 11. Measurement of fluorescence quantum yields: & S37-38 \\
\hline $\begin{array}{l}\text { 12. Determination of incident photon flux }\left(I_{0}\right) \text { of the UV lamp by } \\
\text { potassium ferrioxalate actinometry: }\end{array}$ & S38 \\
\hline $\begin{array}{l}\text { 13. Photochemical quantum yield determination for both the } \\
\text { conjugates, Binol-Cbl and Binol-VPA: }\end{array}$ & $S 39-S 40$ \\
\hline $\begin{array}{l}\text { 14. Calculation of two-photon uncaging cross-section for Binol-Cbl } \\
\text { and Binol-VPA: }\end{array}$ & S41 \\
\hline 15. Two-photon photolysis: & S42 \\
\hline 16. Mechanism of photorelease & S43 - S45 \\
\hline $\begin{array}{l}\text { 17. Experimental procedure for biological application study with } \\
\text { cancerous cell line B16F10 melanoma }\end{array}$ & S46-S49 \\
\hline $\begin{array}{l}\text { 18. Fluorogenic real-time monitoring of drug release study with } \\
\text { MCF-7 cells: }\end{array}$ & S50 \\
\hline 19. Reference: & S51 \\
\hline
\end{tabular}




\section{General experimental details:}

Glassware used in reactions was thoroughly oven-dried. All commercial grade reagents were used without further purification and solvents were dried prior to use following standard protocol. Reactions were monitored by thin layer chromatography (TLC) using Merck silica gel 60 F254 precoated plates $(0.25 \mathrm{~mm})$ and the spots were visualized by exposure to UV light and/or by dipping into $\mathrm{KMnO}_{4}$ solution. Silica gel of particle size 230-400 mesh and petroleum ether/ethyl acetate as eluent were used for column chromatographic purification. ${ }^{1} \mathrm{H}$ and ${ }^{13} \mathrm{C}$ NMR spectra for all the compounds were recorded at 400/600 and 100/150 MHz (Bruker Ultrashield ${ }^{\mathrm{TM}}$ 400, Ascend ${ }^{\mathrm{TM}}$ 600), respectively. The spectra were recorded in deuterochloroform $\left(\mathrm{CDCl}_{3}\right)$, deuterateddimethyl sulfoxide (DMSO- $\left.d_{6}\right)$ and deuterated water $\left(\mathrm{D}_{2} \mathrm{O}\right)$ as solvent at room temperature. Chemical shifts are reported in ppm from tetramethylsilane with the solvent resonance as internal standard $\left(\mathrm{CDCl}_{3}: \delta_{\mathrm{H}}=7.26, \delta_{\mathrm{C}}=77.16 \mathrm{ppm}\right.$ and DMSO- $\left.d_{6}: \delta_{\mathrm{H}}=2.5, \delta_{\mathrm{C}}=39.52 \mathrm{ppm}\right)$. Data for ${ }^{1} \mathrm{H}$ NMR are reported as follows: chemical shift $(\delta \mathrm{ppm})$, multiplicity $(\mathrm{s}=$ singlet, $\mathrm{d}=$ doublet, $\mathrm{t}=$ triplet, $\mathrm{m}=$ multiplet, $\mathrm{dd}=$ doublet of doublet q: quartet, $\mathrm{dt}$ : doublet of triplets, br: broad.), coupling constant $(\mathrm{Hz})$, integration. Data for ${ }^{13} \mathrm{C}$ NMR are reported as chemical shift. UV/vis absorption spectra were recorded on Shimadzu UV-2405 UV/vis spectrophotometer and Shimadzu UV-2600 UV/vis spectrophotometer. Fluorescence emission spectra were recorded on Hitachi F-7000 fluorescence spectrophotometer and Shimadzu RF-6000 spectrofluorophotometer. HRMS spectra were recorded on a JEOL-AccuTOF JMS-T100L mass spectrometer. Photolysis was carried out using $125 \mathrm{~W}$ medium pressure mercury lamp supplied by SAIC (India). RP-HPLC was taken using acetonitrile/water as mobile phase (detection: UV $254 \mathrm{~nm}$ ). 


\section{Synthesis of Binol-VPA, Binol-Cbl and Binol-OMe-VPA:}

Synthesis of our PRPG requires only two simple steps starting from commercially available 2,2'Dimethoxy-1,1'-binaphthalene 1 (Scheme S1). Friedel-Crafts acylation on 1 with bromoacetyl bromide and anhydrous aluminium chloride followed by deprotection of the methyl ether using excess anhydrous aluminium chloride in dry benzene furnished Compound 3. Finally, compound $\mathbf{3}$ was treated with sodium valproate in acetonitrile to give compound 4 (Binol-VPA) and esterification with chlorambucil in presence of $\mathrm{K}_{2} \mathrm{CO}_{3}$ gave compound $\mathbf{5}$ (Binol-Cbl) in almost $70 \%$ and $68 \%$ overall yield respectively. On the other hand, treatment of $\mathbf{2}$ with sodium valproate in acetonitrile gave compound 6 (Binol-VPA-OMe).

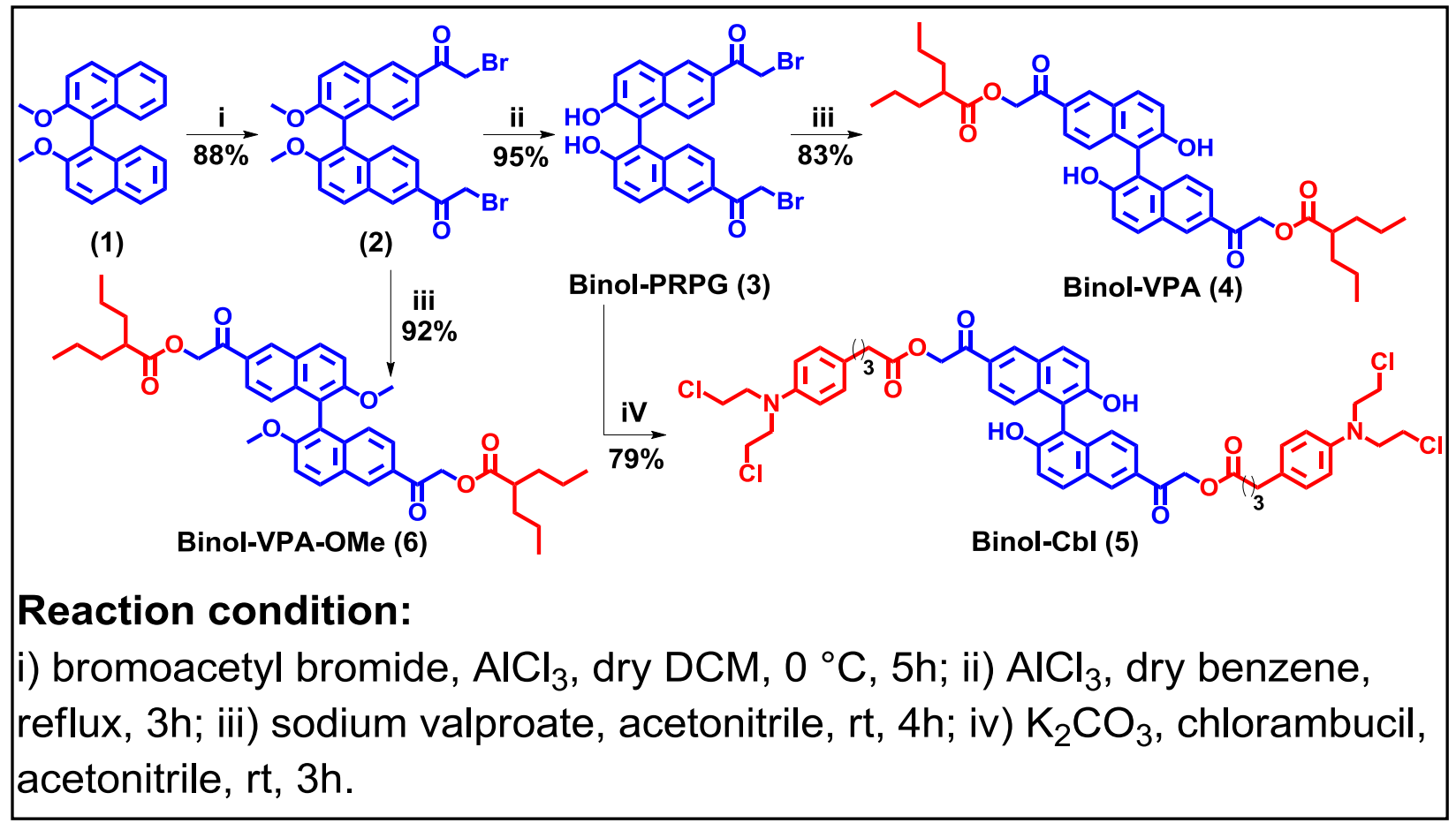

Scheme S1: Synthesis of of Binol-VPA, Binol-VPA-OMe and Binol-Cbl. 


\section{Experimental procedure and Spectroscopic data:}

1,1'-(2,2'-dimethoxy-[1,1'-binaphthalene]-6,6'-diyl)bis(2-bromoethanone) (2) : To a stirred solution of $\mathrm{AlCl}_{3}(587 \mathrm{mg}, 4.4 \mathrm{mmol})$ in $50 \mathrm{~mL}$ dry DCM, bromoacetyl bromide (765 $\mu \mathrm{L}, 4.4 \mathrm{mmol}$ ) in $30 \mathrm{~mL}$ dry $\mathrm{DCM}$ was added dropwise at $0{ }^{\circ} \mathrm{C}$. Stirring was continued for $1 \mathrm{~h}$ at the same temperature, and then a solution of 2,2'-Dimethoxy-1,1'-binaphthalene 1 (630 mg, $2 \mathrm{mmol}$ ) in 30 $\mathrm{mL}$ dry $\mathrm{DCM}$ was added. After $6 \mathrm{~h}$ of stirring at ambient temperature, water was added at $0{ }^{\circ} \mathrm{C}$ to the system slowly maintaining the temperature constant. After usual work-up with DCM and water, the crude product was further purified by silica gel column chromatography using $3 \%$ EtOAc in hexane to afford1,1'-(2,2'-dimethoxy-[1,1'-binaphthalene]-6,6'-diyl)bis(2bromoethanone) (978 mg, $1.76 \mathrm{mmol}$ ) compound 2 in $88 \%$ yield. ${ }^{1} \mathrm{H} \mathrm{NMR}\left(400 \mathrm{MHz}, \mathrm{CDCl}_{3}\right) \delta 8.57$ (s, 2H), 8.15 (d, J = 9.1 Hz, 2H), 7.77 (dd, $J=9.0,1.9 \mathrm{~Hz}, 2 \mathrm{H}), 7.54$ (d, J = 9.1 Hz, 2H), 7.12 (d, $J=9.0$ $\mathrm{Hz}, 2 \mathrm{H}), 4.53$ (s, 4H), $3.82(\mathrm{~s}, 6 \mathrm{H}) .{ }^{13} \mathrm{C}\left\{{ }^{1} \mathrm{H}\right\} \mathrm{NMR}\left(125 \mathrm{MHz}, \mathrm{CDCl}_{3}\right) \delta 191,157.6,136.6,132,131.5$, 129.3, 127.9, 125.7, 124.9, 118.7, 114.5, 56.5, 30.7; HRMS (ESI) m/z: [M + H] $]^{+}$Calcd for $\mathrm{C}_{26} \mathrm{H}_{21} \mathrm{Br}_{2} \mathrm{O}_{4}$ 554.9807; Found 554.9806.

1,1'-(2,2'-dihydroxy-[1,1'-binaphthalene]-6,6'-diyl)bis(2-bromoethanone) (3) : 2-bromo-1-(61,1'-(2,2'-dimethoxy-[1,1'-binaphthalene]-6,6'-diyl)bis(2-bromoethanone) 2 (700 mg, 1.259 $\mathrm{mmol}$ ) was dissolved in $50 \mathrm{~mL}$ dry benzene and ten equivalent of anhydrous $\mathrm{AlCl}_{3}(1.68 \mathrm{~g}, 12.6$ mmol) was added. The solution was heated to reflux for $4 \mathrm{~h}$ in an oil bath, then cooled to $0{ }^{\circ} \mathrm{C}$ and water was added very slowly. Organic solvent was evaporated in rotary evaporator and the water part was extracted three times with EtOAc. The combined organic part was washed with brine, dried over anhydrous $\mathrm{Na}_{2} \mathrm{SO}_{4}$ and concentrated. The crude product was triturated with hexane to afford compound 3 (632 mg, $1.196 \mathrm{mmol}$ ) in excellent yield $95 \% .{ }^{1} \mathrm{H} \mathrm{NMR}\left(400 \mathrm{MHz}, \mathrm{CDCl}_{3}\right) \delta 8.58$ $(\mathrm{d}, J=1.7 \mathrm{~Hz}, 2 \mathrm{H}), 8.15(\mathrm{~d}, J=9.0 \mathrm{~Hz}, 2 \mathrm{H}), 7.86(\mathrm{dd}, J=8.9,1.8 \mathrm{~Hz}, 2 \mathrm{H}), 7.49(\mathrm{~d}, J=9.0 \mathrm{~Hz}, 2 \mathrm{H}), 7.17$ $(\mathrm{d}, J=8.8 \mathrm{~Hz}, 2 \mathrm{H}), 5.41(\mathrm{~s}, 2 \mathrm{H}), 4.51(\mathrm{~s}, 4 \mathrm{H}) .{ }^{13} \mathrm{C}\left\{{ }^{1} \mathrm{H}\right\} \mathrm{NMR}\left(125 \mathrm{MHz}, \mathrm{CDCl}_{3}\right) \delta 191,155.5,136.4$, 133.6, 131.5, 129.8, 128.5, 126.3, 124.8, 119.2, 110.8, 30.5; HRMS (ESI) m/z: $[\mathrm{M}+\mathrm{H}]^{+}$Calcd for : $\mathrm{C}_{24} \mathrm{H}_{17} \mathrm{Br}_{2} \mathrm{O}_{4}$ Exact Mass: 526.9494; Found 526.9502. 


\section{(2,2'-dihydroxy-[1,1'-binaphthalene]-6,6'-diyl)bis(2-oxoethane-2,1-diyl)}

propylpentanoate) (4) : Compound 3 (300 $\mathrm{mg}, 0.568 \mathrm{mmol}$ ) was dissolved in $30 \mathrm{~mL}$ acetonitrile and to this stirred solution, sodium valproate $(208 \mathrm{mg}, 1.25 \mathrm{mmol}$ ) was added and stirred for overnight at room temperature. Solvent was evaporated and water was added to the mixture and extracted with EtOAc three times. The combined organic layer was washed with brine and dried over $\mathrm{Na}_{2} \mathrm{SO}_{4}$ and concentrated. Further purification was achieved by silica gel column chromatography using 25\% EtOAc in hexane to afford compound 4 (309 mg, $0.472 \mathrm{mmol}$ ) in $83 \%$ yield. ${ }^{1} \mathrm{H}$ NMR $\left(400 \mathrm{MHz}, \mathrm{CDCl}_{3}\right) \delta 8.43(\mathrm{~s}, 2 \mathrm{H}), 8.04(\mathrm{~d}, J=9.0 \mathrm{~Hz}, 2 \mathrm{H}), 7.75(\mathrm{~d}, J=8.9 \mathrm{~Hz}, 2 \mathrm{H}), 7.45$ (d, $J=9.0 \mathrm{~Hz}, 2 \mathrm{H}$ ), $7.12(\mathrm{~d}, J=8.8 \mathrm{~Hz}, 2 \mathrm{H}), 5.66(\mathrm{~s}, 2 \mathrm{H}), 5.39(\mathrm{~s}, 4 \mathrm{H}), 2.55(\mathrm{dq}, J=9.0,5.1 \mathrm{~Hz}, 2 \mathrm{H}$ ), $1.80-1.64(\mathrm{~m}, 4 \mathrm{H}), 1.55-1.44(\mathrm{~m}, 4 \mathrm{H}), 1.43-1.31(\mathrm{~m}, 8 \mathrm{H}), 0.91(\mathrm{t}, J=7.2 \mathrm{~Hz}, 12 \mathrm{H}) .{ }^{13} \mathrm{C}\left\{{ }^{1} \mathrm{H}\right\} \mathrm{NMR}$ $\left(125 \mathrm{MHz}, \mathrm{CDCl}_{3}\right) \delta 192,176.1,155.4,136.4,133.2,130.1,130,128.3,125.1,124.8,119.3,111.3$, 65.7, 45.1, 34.6, 29.7, 20.6, 14; HRMS (ESI) m/z: [M + H] ${ }^{+}$Calcd for $\mathrm{C}_{40} \mathrm{H}_{47} \mathrm{O}_{8} 655.3271$; Found 655.3275 .

\section{(2,2'-dihydroxy-[1,1'-binaphthalene]-6,6'-diyl)bis(2-oxoethane-2,1-diyl)}

(dipropylamino)phenyl)butanoate) (5): To a $50 \mathrm{~mL}$ round-bottom flask, chlorambucil (256 mg, $0.833 \mathrm{mmol})$ in $150 \mathrm{~mL}$ acetonitrile was dissolved and $\mathrm{K}_{2} \mathrm{CO}_{3}(160 \mathrm{mg}, 0.1 .14 \mathrm{mmol})$ was added. The solution was stirred for $20 \mathrm{~min}$, then a solution of compound $\mathbf{3}$ ( $200 \mathrm{mg}, 0.379 \mathrm{mmol}$ ) in 10 $\mathrm{mL}$ acetonitrile was added. After stirring for $3 \mathrm{~h}$ at ambient temperature, solvent was evaporated. Water was added to the mixture and extracted with EtOAc three times. The combined organic layer was washed with aqueous sodium bicarbonate, brine and dried over $\mathrm{Na}_{2} \mathrm{SO}_{4}$ and concentrated. Further purification was achieved by silica gel column chromatography using $30 \%$ EtOAc in hexane to afford compound $4(268 \mathrm{mg}, 0.3 \mathrm{mmol})$ in $79 \%$ yield. ${ }^{1} \mathrm{H} \mathrm{NMR}\left(400 \mathrm{MHz}, \mathrm{CDCl}_{3}\right.$ ) $\delta 8.41(\mathrm{~s}, 1 \mathrm{H}), 8.05(\mathrm{~d}, J=9.0 \mathrm{~Hz}, 1 \mathrm{H}), 7.73(\mathrm{~d}, J=8.9 \mathrm{~Hz}, 1 \mathrm{H}), 7.46(\mathrm{~d}, J=8.9 \mathrm{~Hz}, 1 \mathrm{H}), 7.12$ (dd, $J=$ $12.3,8.7 \mathrm{~Hz}, 3 \mathrm{H}), 6.65(\mathrm{~d}, J=8.4 \mathrm{~Hz}, 2 \mathrm{H}), 5.92(\mathrm{~s}, 1 \mathrm{H}), 5.38(\mathrm{~s}, 2 \mathrm{H}), 3.88-3.67(\mathrm{~m}, 4 \mathrm{H}), 3.63(\mathrm{t}, J=$ $6.9 \mathrm{~Hz}, 4 \mathrm{H}), 2.63(\mathrm{t}, J=7.5 \mathrm{~Hz}, 2 \mathrm{H}), 2.52(\mathrm{t}, J=7.4 \mathrm{~Hz}, 2 \mathrm{H}), 2.07-1.93(\mathrm{~m}, 2 \mathrm{H}) .{ }^{13} \mathrm{C}\left\{{ }^{1} \mathrm{H}\right\} \mathrm{NMR}(125$ $\left.\mathrm{MHz}, \mathrm{CDCl}_{3}\right) \delta 191.8,173.2,155.5,144.2,136.6,133.2,130.9,130,130,128.3,125,124.9,119.4$, 112.5, 111.5, 65.9, 53.7, 40.5, 33.9, 33.2, 26.7; HRMS (ESI) m/z: $[\mathrm{M}+\mathrm{H}]^{+}$Calcd for $\mathrm{C}_{52} \mathrm{H}_{53} \mathrm{Cl}_{4} \mathrm{~N}_{2} \mathrm{O}_{8}$ 973.2556; Found 973.2562. 


\section{(2,2'-dimethoxy-[1,1'-binaphthalene]-6,6'-diyl)bis(2-oxoethane-2,1-diyl)}

bis(2-

propylpentanoate) (6): Compound 2 (100 mg, $0.18 \mathrm{mmol}$ ) was dissolved in $20 \mathrm{~mL}$ acetonitrile and to this stirred solution, sodium valproate $(66 \mathrm{mg}, 0.396 \mathrm{mmol}$ ) was added and stirred for overnight at room temperature. Solvent was evaporated and water was added to the mixture and extracted with EtOAc three times. The combined organic layer was washed with brine and dried over $\mathrm{Na}_{2} \mathrm{SO}_{4}$ and concentrated. Further purification was achieved by silica gel column chromatography using $10 \%$ EtOAc in hexane to afford compound 6 (113 mg, $0.166 \mathrm{mmol})$ in $92 \%$ yield. ${ }^{1} \mathrm{H}$ NMR (400 $\mathrm{MHz}_{\mathrm{CDCl}}$ ) $\delta 8.49(\mathrm{~s}, 2 \mathrm{H}), 8.12(\mathrm{~d}, J=9.1 \mathrm{~Hz}, 2 \mathrm{H}), 7.71(\mathrm{dd}, J=8.9,1.7 \mathrm{~Hz}, 2 \mathrm{H}), 7.53(\mathrm{~d}, J=9.1 \mathrm{~Hz}$, 2H), $7.11(\mathrm{~d}, J=8.9 \mathrm{~Hz}, 2 \mathrm{H}), 5.42(\mathrm{~s}, 4 \mathrm{H}), 3.80(\mathrm{~s}, 6 \mathrm{H}), 2.66-2.43(\mathrm{~m}, 2 \mathrm{H}), 1.78-1.64(\mathrm{~m}, 4 \mathrm{H}), 1.56$ - $1.30(\mathrm{~m}, 14 \mathrm{H}), 0.92(\mathrm{t}, J=7.2 \mathrm{~Hz}, 13 \mathrm{H}) .{ }^{13} \mathrm{C}\left\{{ }^{1} \mathrm{H}\right\} \mathrm{NMR}\left(125 \mathrm{MHz}, \mathrm{CDCl}_{3}\right) \delta$ 192.1, 176, 157.3, 136.5, 131.8, 130, 129.7, 127.9, 125.6, 124, 118.7, 114.5, 77.3, 77, 76.8, 65.6, 56.5, 45.1, 34.6, 29.7, 20.6, 14. HRMS (ESI) m/z: [M+ H] ${ }^{+}$Calcd for $\mathrm{C}_{42} \mathrm{H}_{51} \mathrm{O}_{8} 683.3584$; Found 683.3602. 
4. ${ }^{1} \mathrm{H}$ and ${ }^{13} \mathrm{C}$ NMR Spectra:

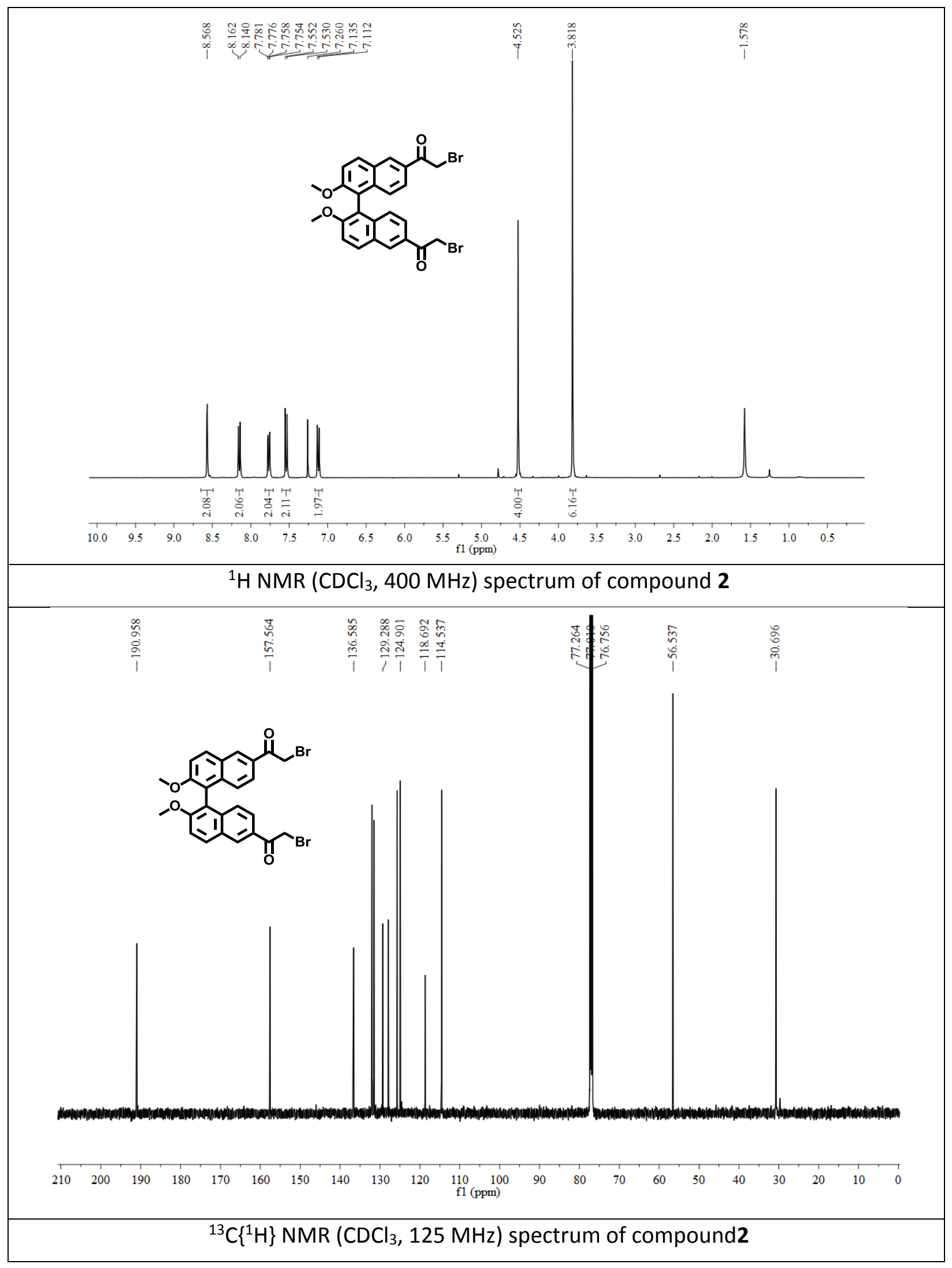




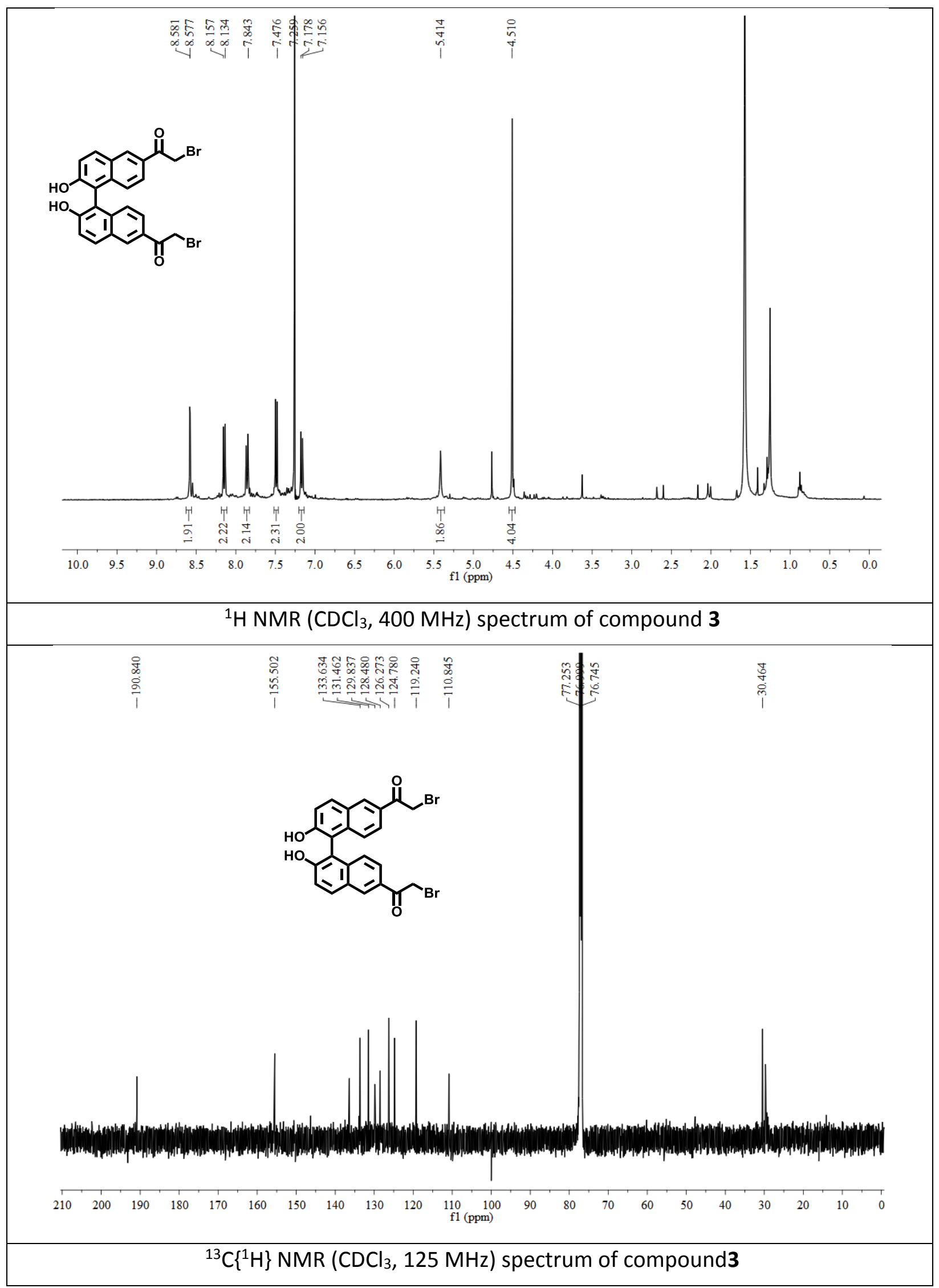




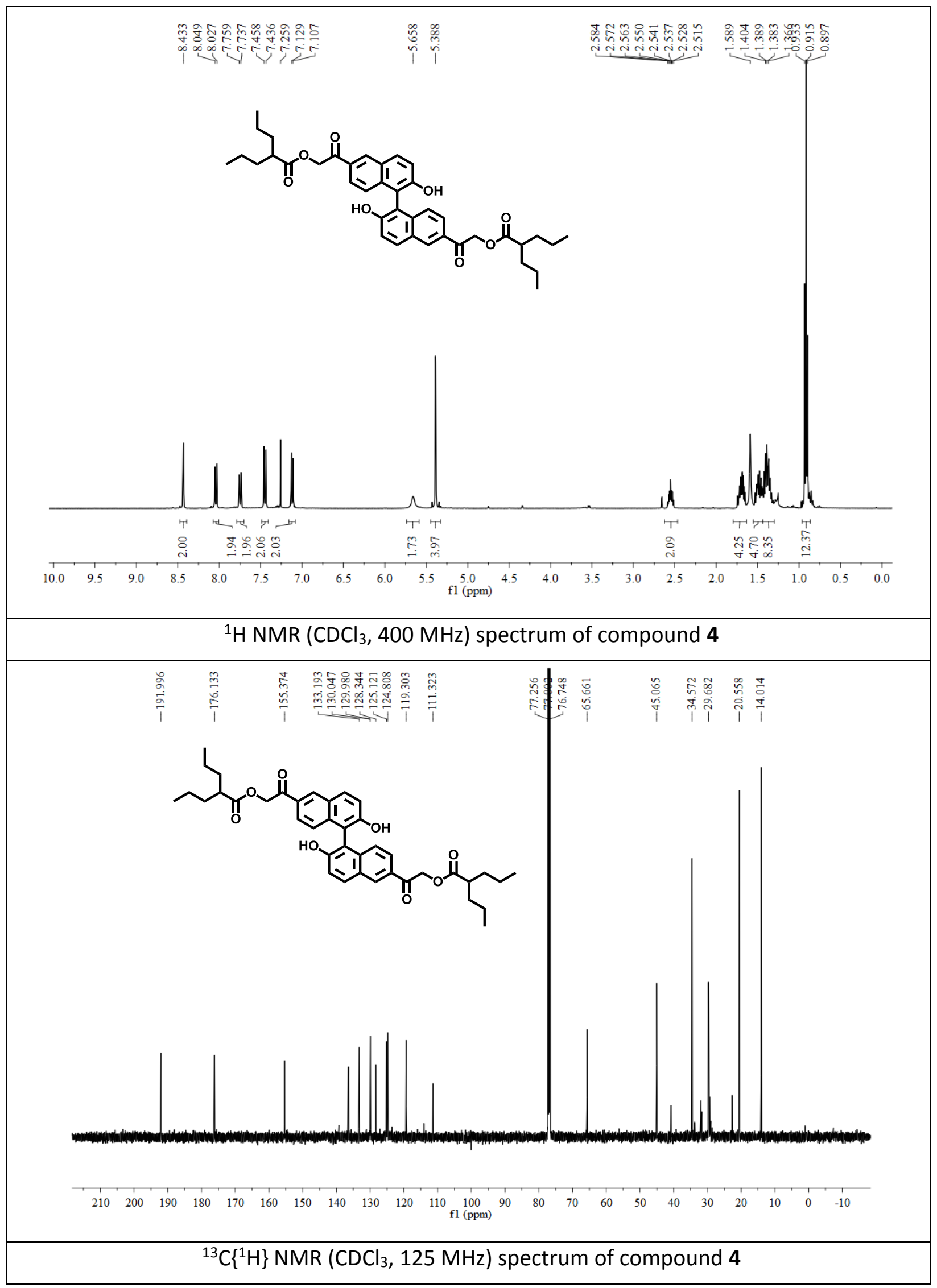




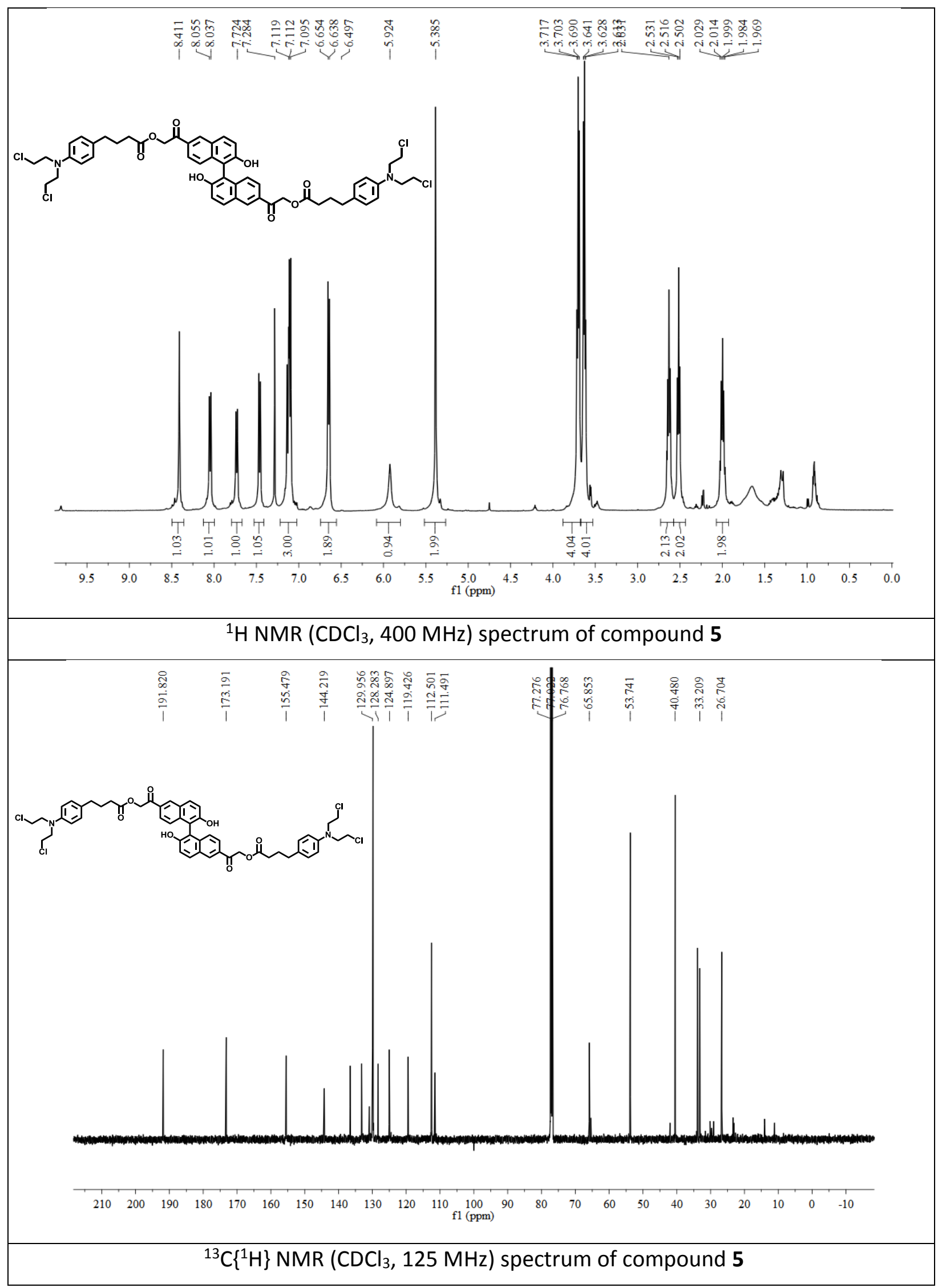




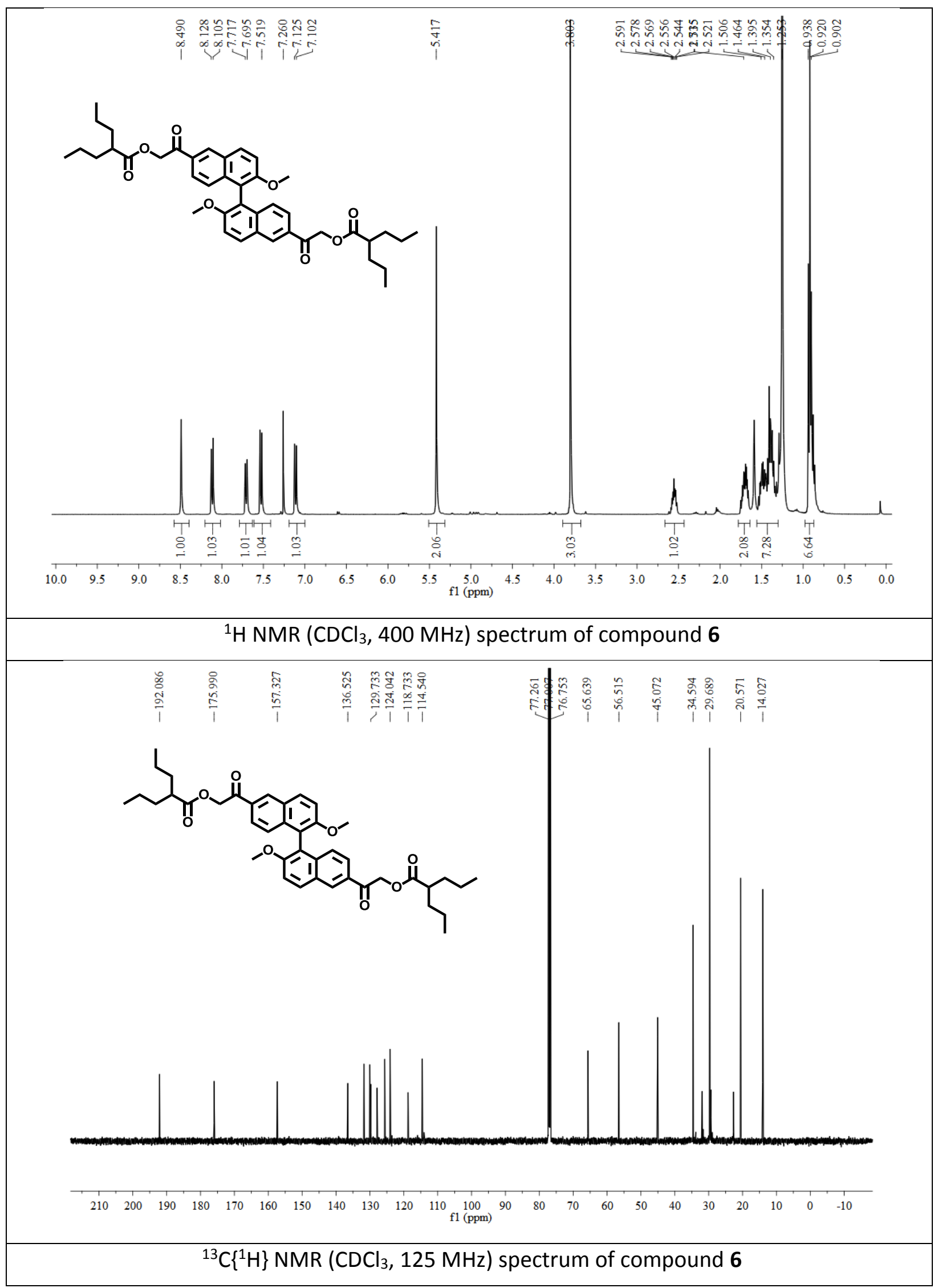




\section{RP-HPLC of Binol-VPA, Binol-Cbl and Binol-VPA-OMe:}

We checked the purity of all our drug delivery systems using RP-HPLC and found that all the three DDSs namely, Binol-VPA, Binol-Cbl and Binol-VPA-OMe are $96 \%, 97 \%$ and $99 \%$ pure respectively (Figure S1).

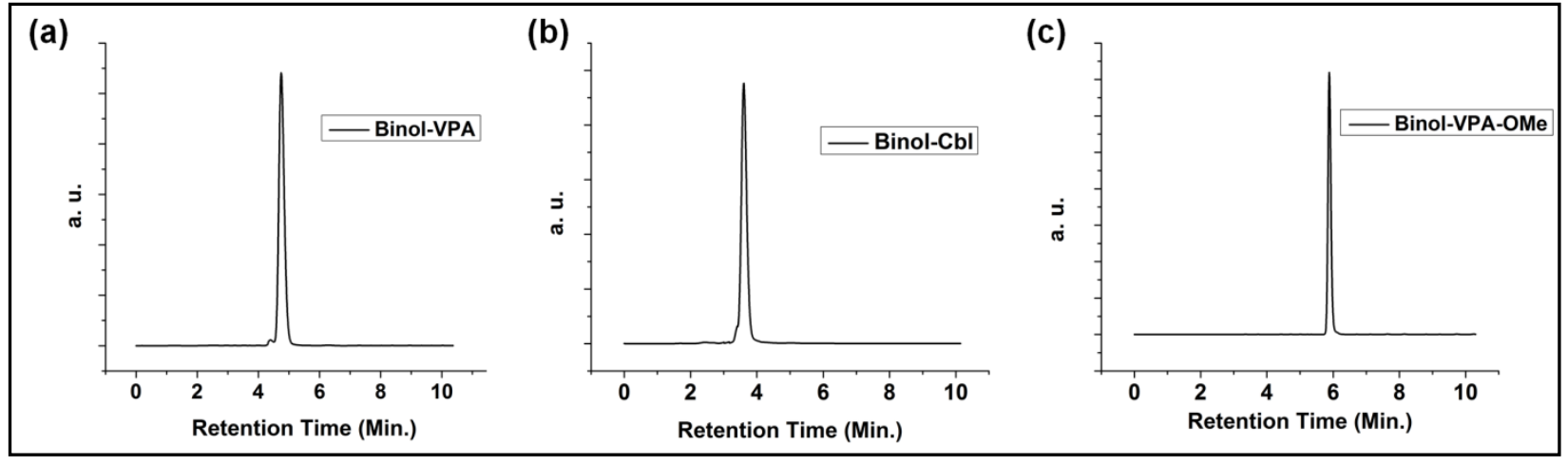

Figure S1: RP-HPLC diagram of (a) Binol-VPA, (b) Binol-Cbl and (c) Binol-VPA-OMe.

\section{Photophysical properties:}

\subsection{Absorption and emission spectra of Binol-VPA:}

The absorption and emission spectra of Binol-VPA in different solvents were recorded on a UVVis absorbance and fluorescence spectrophotometer respectively. In each case, a $\left(1 \times 10^{-4} \mathrm{M}\right)$ solution was prepared with different solvents and after degassing the solution the spectra were taken (Figure S2).
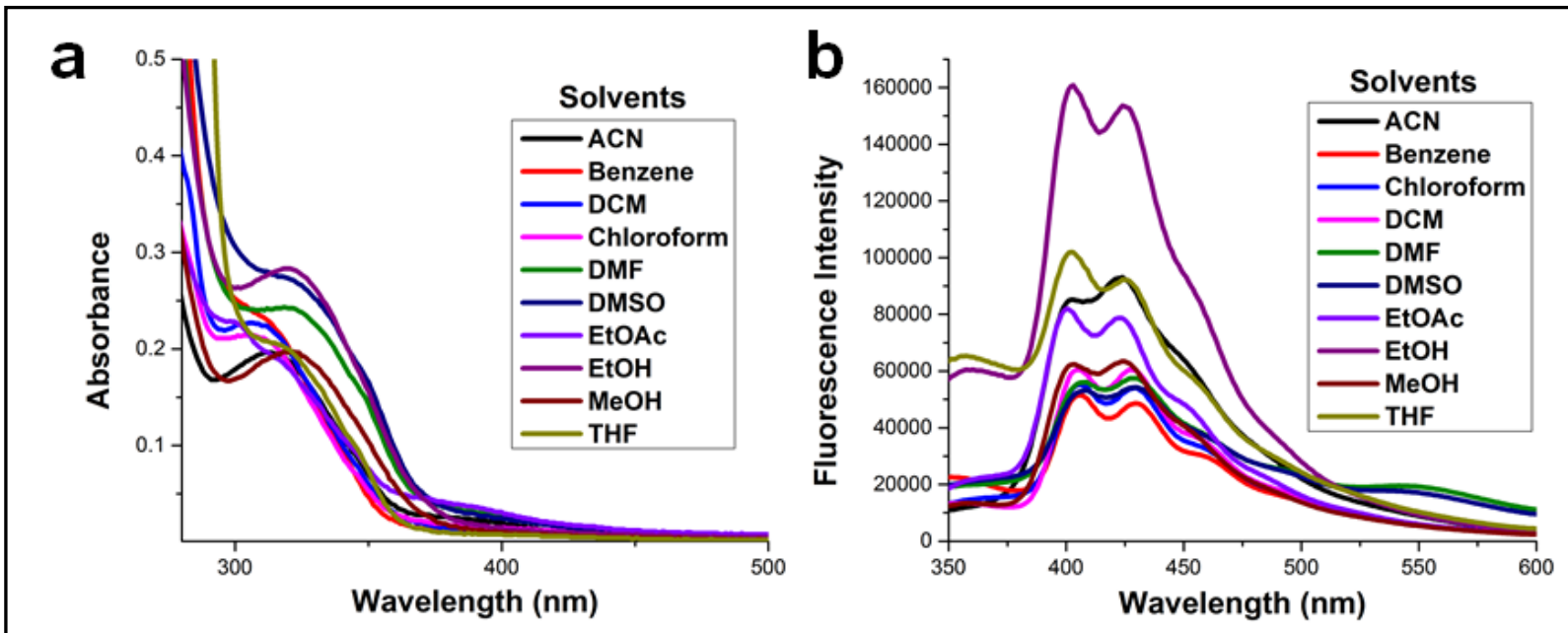

Figure S2: (a) UV-Vis absorbance spectra and (b) fluorescence spectra of Binol-VPA in different solvent 


\subsection{Absorption and emission spectra of Binol-Cbl:}

The absorption and emission spectra of Binol-Cbl in different solvents were recorded on a UV-Vis absorbance and fluorescence spectrophotometer respectively. In each case, a $\left(1 \times 10^{-4} \mathrm{M}\right)$ solution was prepared with different solvents and after degassing the solution the spectra were taken (Figure S3).

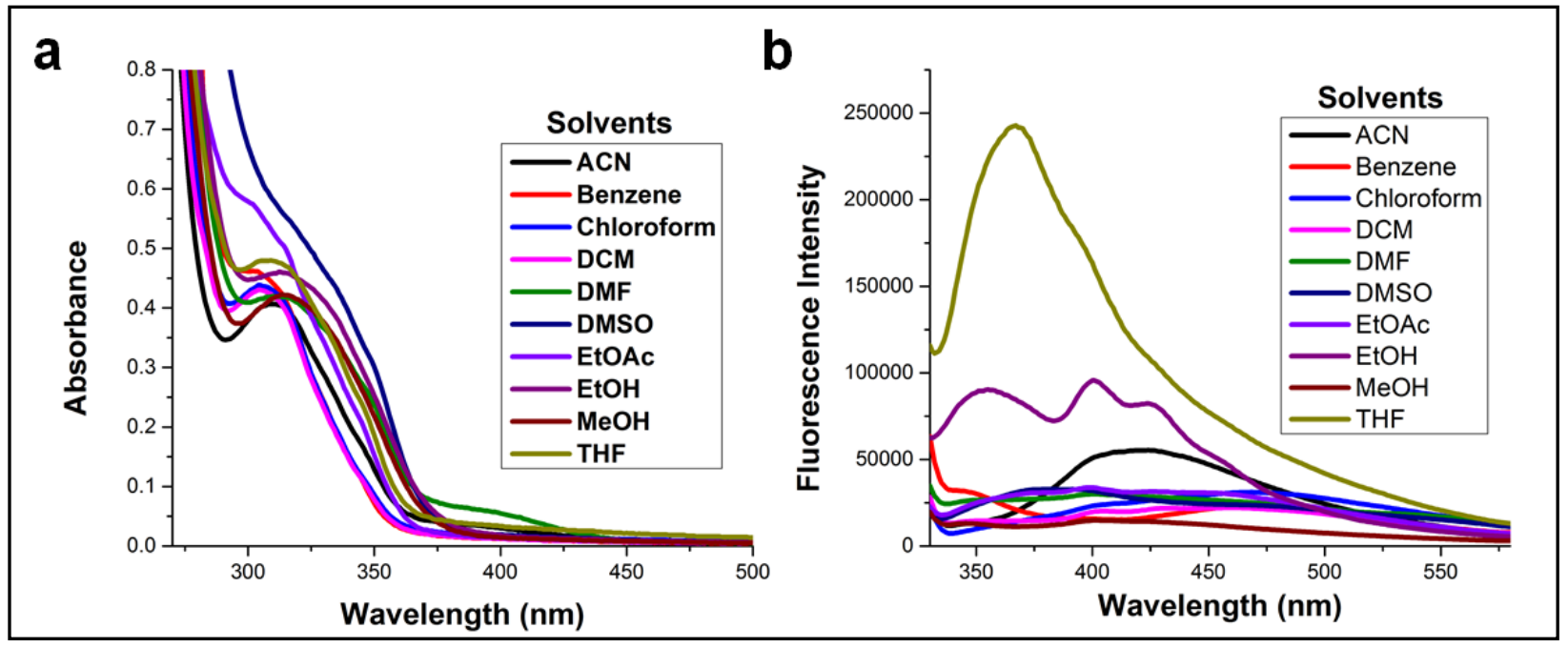

Figure S3: (a) UV-Vis absorbance spectra and (b) fluorescence spectra of Binol-Cbl in different solvent 


\subsection{Absorption and emission spectra of Binol-VPA with different $\mathrm{pHs}$ and dilute $\mathrm{NaOH}$ solution:}

The absorption and emission spectra of Binol-VPA was recorded on a UV-Vis absorbance and fluorescence spectrophotometer using different solvent mixtures of $90 \%$ DMSO and 10\% buffer of $\mathrm{pH}-5, \mathrm{pH}-7.4$ and dilute $\mathrm{NaOH}$. In each case, a $\left(1 \times 10^{-4} \mathrm{M}\right)$ solution was prepared and after degassing the solution the spectra were taken (Figure S4).

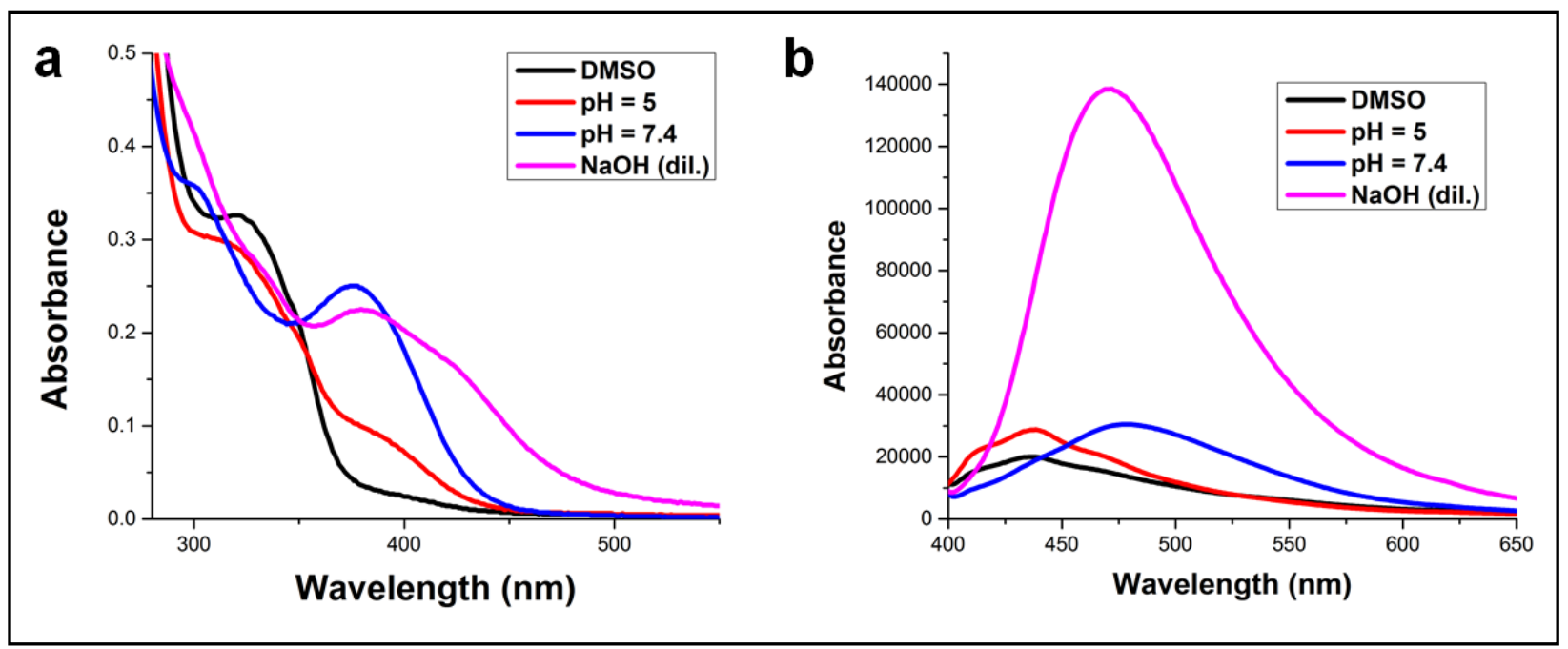

Figure S4: (a) UV-Vis absorbance spectra and (b) fluorescence spectra of Binol-VPA with different solvent mixturesin 90\% DMSO and $10 \%$ buffer of $\mathrm{pH}-5, \mathrm{pH}-7.4$ and dilute $\mathrm{NaOH}$. 


\subsection{Absorption and emission spectra of Binol-VPA with $\mathrm{NaOH}$ solution of different concentration:}

The absorption and emission spectra of Binol-VPA in DMSO with gradual addition of dilute and concentrated $\mathrm{NaOH}$ were recorded on a UV-Vis absorbance and fluorescence spectrophotometer. In each case, approximately $\left(1 \times 10^{-4} \mathrm{M}\right)$ solution was prepared and after degassing the solution the spectra were taken (Figure S5).

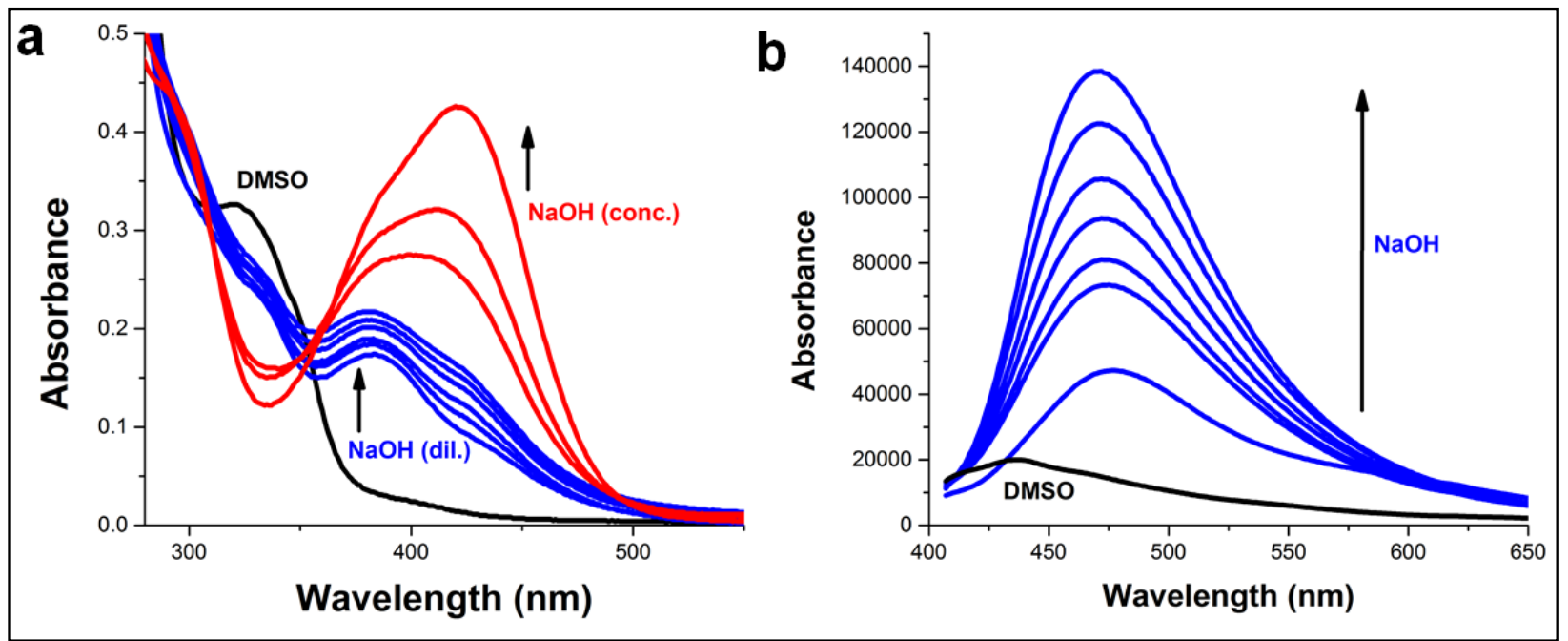

Figure S5: (a) UV-Vis absorbance spectra and (b) fluorescence spectra of Binol-VPA in DMSO with gradual addition of dilute and concentrated $\mathrm{NaOH}$. 


\subsection{Absorption and emission spectra of Binol-VPA-OMe with different pHs:}

The absorption and emission spectra of Binol-VPA-OMe was recorded on a UV-Vis absorbance and fluorescence spectrophotometer using different solvent mixtures of 90\% DMSO and $10 \%$ buffer of $\mathrm{pH}-5, \mathrm{pH}-7.4$. In each case, a $\left(1 \times 10^{-4} \mathrm{M}\right)$ solution was prepared and after degassing the solution the spectra were taken (Figure S6).

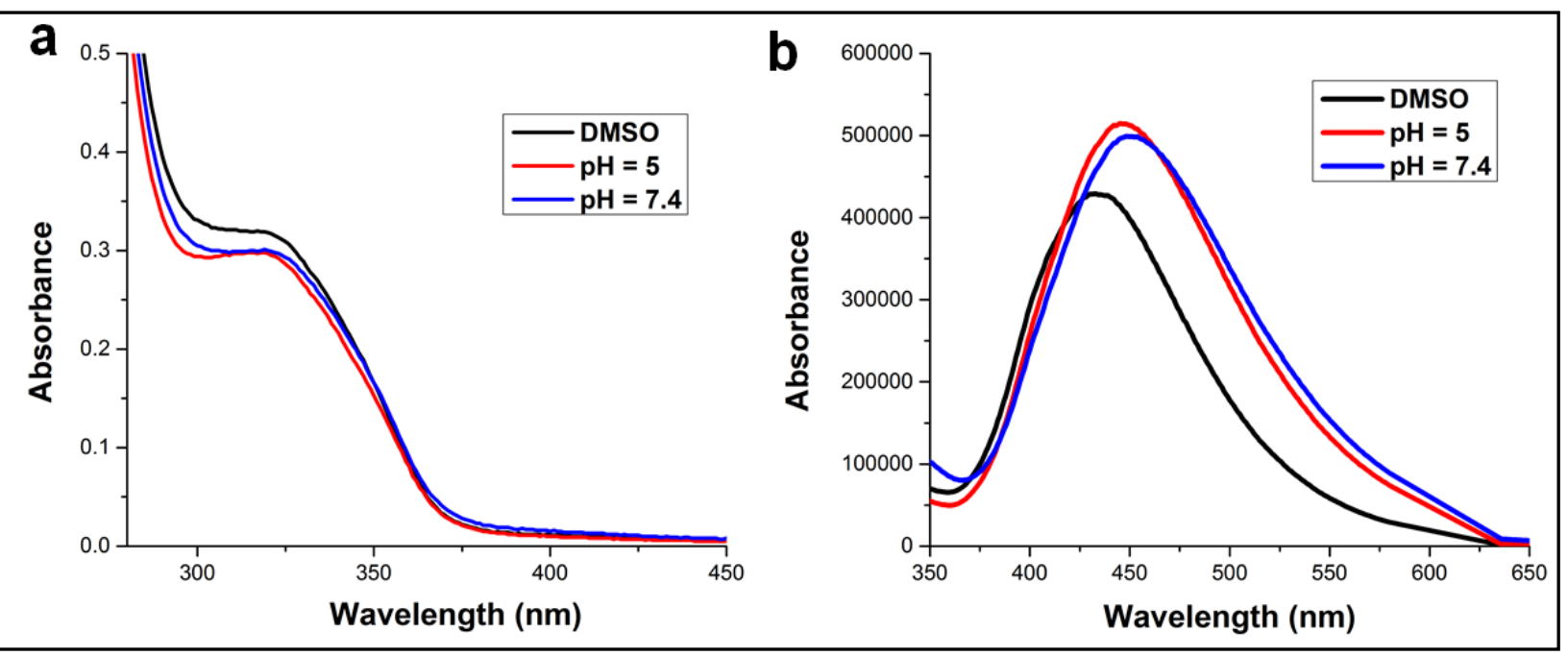

Figure S6: (a) UV-Vis absorbance spectra and (b) fluorescence spectra of Binol-VPA in DMSO and with different solvent mixture of $90 \% \mathrm{DMSO}$ and $10 \%$ buffer of $\mathrm{pH}-5, \mathrm{pH}-7.4$. 


\subsection{Absorption and emission spectra of Binol-VPA with DMSO buffer mixture with different $f_{\mathrm{w}}$ :}

The absorption and emission spectra of Binol-VPA was recorded on a UV-Vis and fluorescence spectrophotometer in DMSO / buffer $(\mathrm{pH}-7.4)$ binary mixture with different water fraction $\left(f_{\mathrm{w}}\right)$. In each case, a $\left(1 \times 10^{-4} \mathrm{M}\right)$ solution was prepared and after degassing the solution the spectra were taken (Figure S7).
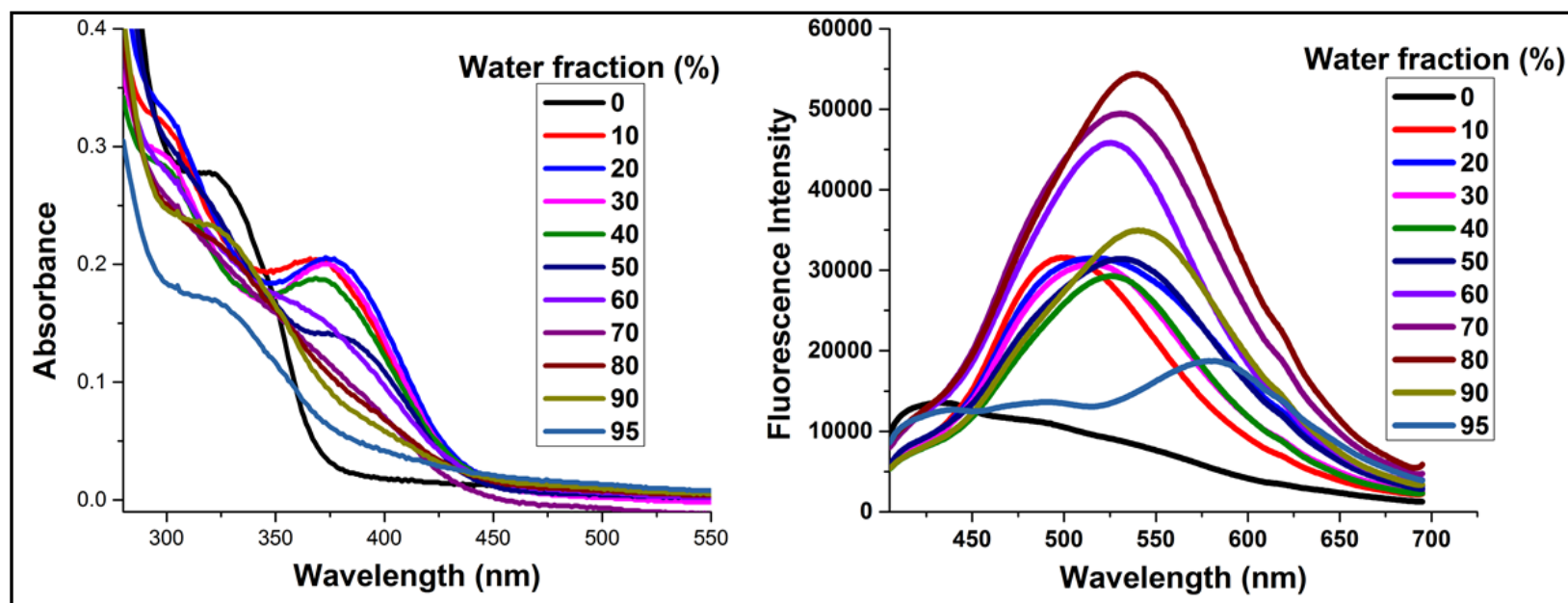

Figure S7: (a) UV-Vis absorbance spectra and (b) fluorescence spectra of Binol-VPA in DMSO / buffer $(\mathrm{pH}-7.4)$ binary mixture with different water fraction $\left(f_{\mathrm{w}}\right)$. 


\section{Z-scan measurement:}

An open aperture z-scan measurement ${ }^{1}$ was performed with Ti:Sapphire laser tuning the wavelength from $700 \mathrm{~nm}-850 \mathrm{~nm}$. Laser beam was focused to a spot size of $50 \mu \mathrm{m}$ with a $15 \mathrm{~cm}$ plano-convex lens. Incident laser power on the sample was fixed at $1 \mathrm{~W}$ with a linearly varying ND filter. All the sample solutions were kept in a $2 \mathrm{~mm}$ path length quartz cuvette with a constant magnetic stirring system. The sample cuvette was moved along the laser beam across the focus through a motorized translational stage (Newport, ESP301). Rayleigh range $\left(Z_{R}\right)$ was $3.9 \mathrm{~mm}$. The transmitted laser beam was collected by another plano-convex lens of 2 inch diameter and $20 \mathrm{~cm}$ focal length and detected with an amplified Si-photodiode (Thorlabs PDA100A-EC). Data is taken through an oscilloscope (Tektronix DPO 4054). The experimental curve was fitted with transmission equation involving two-photon absorption [equation (1)]. ${ }^{2}$

$$
T(z)=\sum_{n=0}^{\infty} \frac{\left(-q_{0}\right)^{n}}{(n+1)^{\frac{3}{2}}\left(1+x^{2}\right)^{n}} \ldots \ldots(1)
$$

Where, $x=z / z_{R}, q_{0}=\beta L_{e f f} I_{0} ; I_{0}$ is the maximum on-axis intensity in the focus, $\beta$ is TPA coefficient and $z_{R}$ is the Rayleigh length.

With the value $\beta$ extracted from the Eq. (1) TPA cross section has been determined by Eq. (2).

$$
\sigma=\sum_{n=0}^{\infty} \frac{h \beta}{N_{A} \rho \lambda \times 10^{-3}} \ldots \ldots
$$

Where, $h$ is the Planck constant, $\mathrm{N}_{\mathrm{A}}$ is Avogadro's number, $\lambda$ is wavelength of the laser and $\rho$ is the concentration in mole per litre. $\sigma$ is expressed in a SI unit (GM) defined as $1 \mathrm{GM}=10^{-50} \mathrm{~cm}^{4} \mathrm{~s}$ photon $^{-1}$ molecule $^{-1}$. 


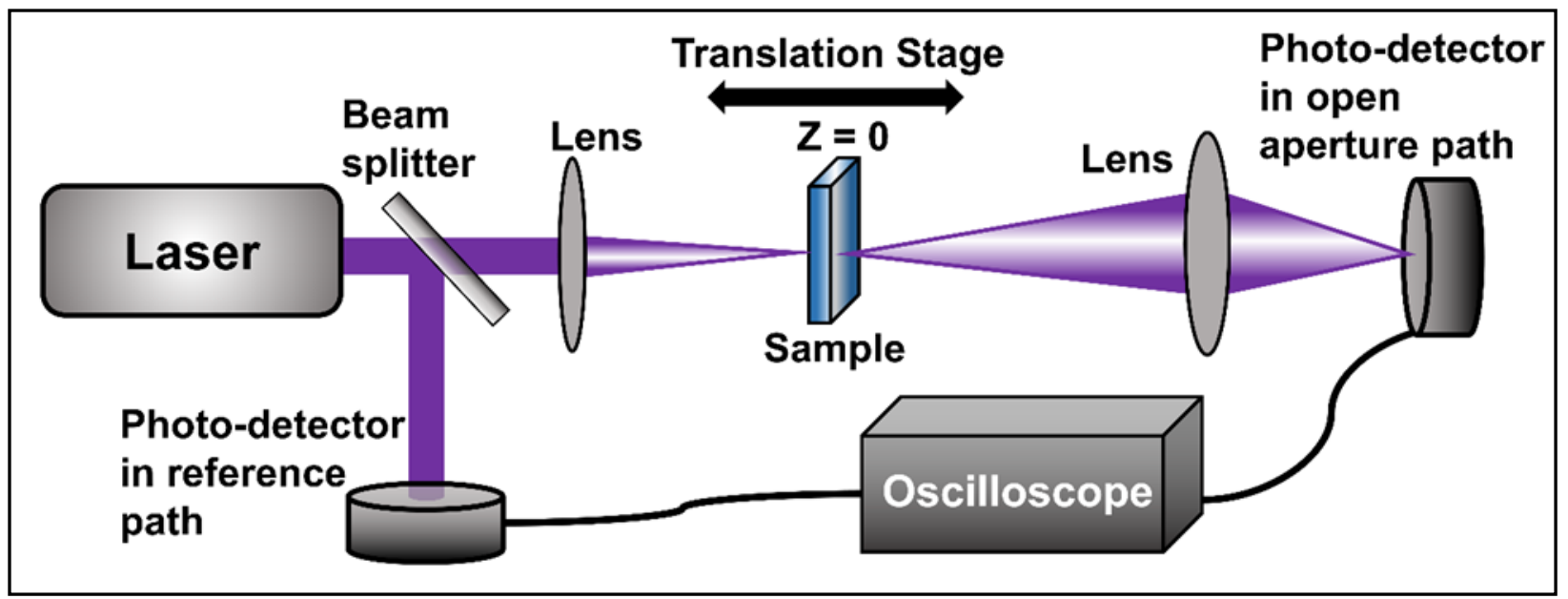

Figure S8: Schematic of open-aperture z-scan technique. 


\subsection{TPA cross-section of Binol-VPA and Binol-Cbl at different wavelengths:}

The two-photon absorption cross section $\delta a$ was meassured for both the conjugates, Binol-VPA and Binol-Cbl at different wavelengths with a $\left(1 \times 10^{-4} \mathrm{M}\right)$ solution in DMSO / buffer $(\mathrm{pH}-7.4)$ binary mixture $\left(f_{\mathrm{w}}=20\right)$ was taken in each cases, The experimental OA curves (Figure S9 \& S10) was then fitted with the transmission equation with two-photon absorption (TPA) phenomenon. ${ }^{1}$ The TPA cross-section $\delta_{a}$ is calculated ${ }^{2}$ for both the DDS and summarised in table S1.

\begin{tabular}{|c|c|c|c|c|c|c|}
\hline \multirow{2}{*}{} & \multicolumn{5}{|c|}{ TPA cross-section at different wavelengths in GM } \\
\cline { 2 - 7 } DDS & $\mathbf{7 0 0} \mathbf{~ n m}$ & $\mathbf{7 2 0} \mathbf{~ n m}$ & $\mathbf{7 5 0} \mathbf{~ n m}$ & $\mathbf{7 8 0} \mathbf{n m}$ & $\mathbf{8 1 0} \mathbf{~ n m}$ & $\mathbf{8 4 0} \mathbf{~ n m}$ \\
\hline Binol-CbI & 119 & 140 & 135 & 112 & 91 & 76 \\
\hline Binol-VPA & 98 & 100 & 110 & 103 & 80 & 69 \\
\hline
\end{tabular}

Table S1: The two-photon absorption cross section $\delta a$ was meassured for both the conjugates, Binol-VPA and Binol-Cbl at different wavelengths with a $\left(1 \times 10^{-4} \mathrm{M}\right)$ solution in DMSO / buffer $(\mathrm{pH}-7.4)$ binary mixture $\left(f_{\mathrm{w}}=20\right)$ was taken in each cases 


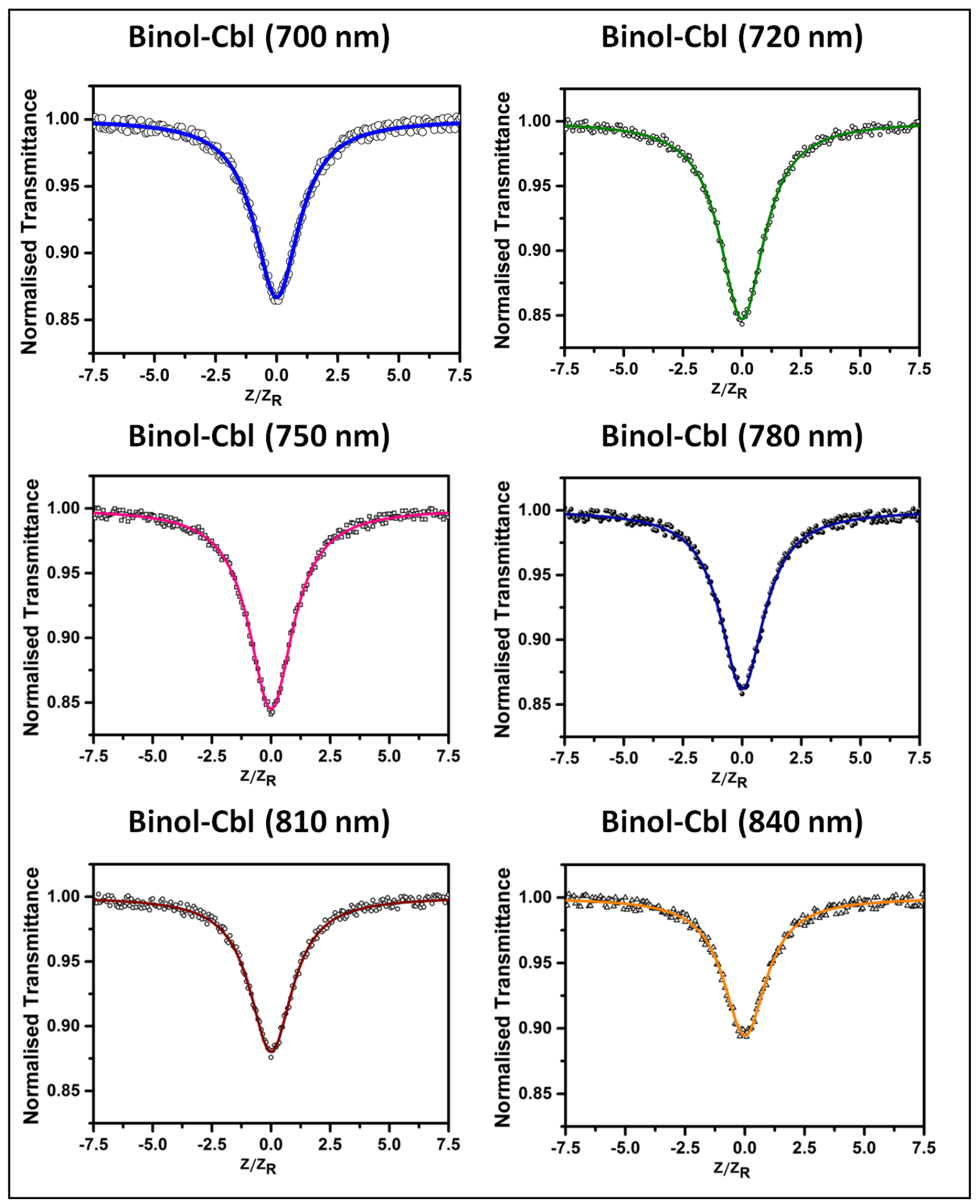

Figure S9: Open aperture (OA) Z-scan data of Binol-Cbl in DMSO / buffer ( $\mathrm{pH}$ - 7.4) binary mixture of $\mathrm{fw}=20 \%$ at different wavelengths, ranging from $700 \mathrm{~nm}$ to $850 \mathrm{~nm}$. The solid line represents theoretical fitting by Eq. (1). 


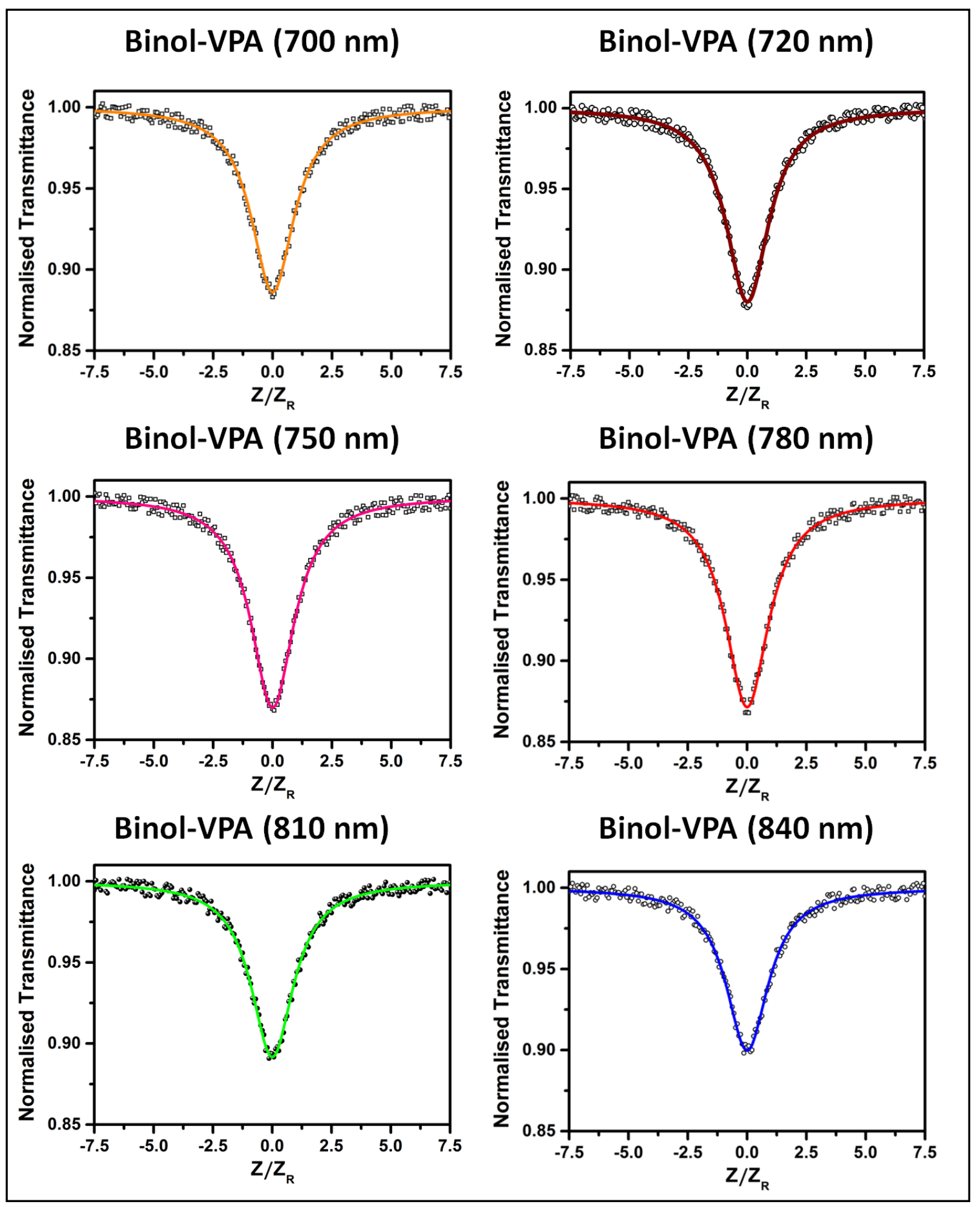

Figure S10: Open aperture (OA) Z-scan data of Binol-Cbl in DMSO / buffer (pH - 7.4) binary mixture of $\mathrm{fw}=20 \%$ at different wavelengths, ranging from $700 \mathrm{~nm}$ to $850 \mathrm{~nm}$. The solid line represents theoretical fitting by Eq. (1). 


\subsection{TPA cross-section at different water fractions for Binol-VPA and Binol-Cbl:}

The two-photon absorption cross section $\delta a$ was meassured for both the conjugates, Binol-VPA and Binol-Cbl with a $\left(1 \times 10^{-4} \mathrm{M}\right)$ solution inDMSO / buffer $(\mathrm{pH}-7.4)$ binary mixture with variying water fraction at $800 \mathrm{~nm}$ in all cases. The experimental OA curves (Figure S11 \& S12) was then fitted with the transmission equation with two-photon absorption (TPA) phenomenon. ${ }^{1}$ The TPA cross-section $\delta_{a}$ is calculated ${ }^{2}$ for both the DDS and summarised in Table S2.

\begin{tabular}{|c|c|c|c|c|c|c|}
\hline \multirow{2}{*}{} & \multicolumn{5}{|c|}{ TPA cross-section at different water fraction $\left(f_{\mathrm{w}}\right)$ in GM } \\
\cline { 2 - 7 } DDS & $f_{\mathrm{w}}=\mathbf{0}$ & $f_{\mathrm{w}}=\mathbf{2 0}$ & $f_{\mathrm{w}}=\mathbf{4 0}$ & $f_{\mathrm{w}}=\mathbf{6 0}$ & $f_{\mathrm{w}}=\mathbf{8 0}$ & $f_{\mathrm{w}}=90$ \\
\hline Binol-CbI & 40 & 103 & 106 & 91 & 86 & 68 \\
\hline Binol-VPA & 30 & 102 & 91 & 70 & 61 & 51 \\
\hline
\end{tabular}

Table S2: The two-photon absorption cross section $\delta a$ was meassured for both the conjugates, Binol-VPA and Binol-Cbl with a $\left(1 \times 10^{-4} \mathrm{M}\right)$ solution in DMSO / buffer $(\mathrm{pH}-7.4)$ binary mixture with variying water fraction at $800 \mathrm{~nm}$ in all cases. 

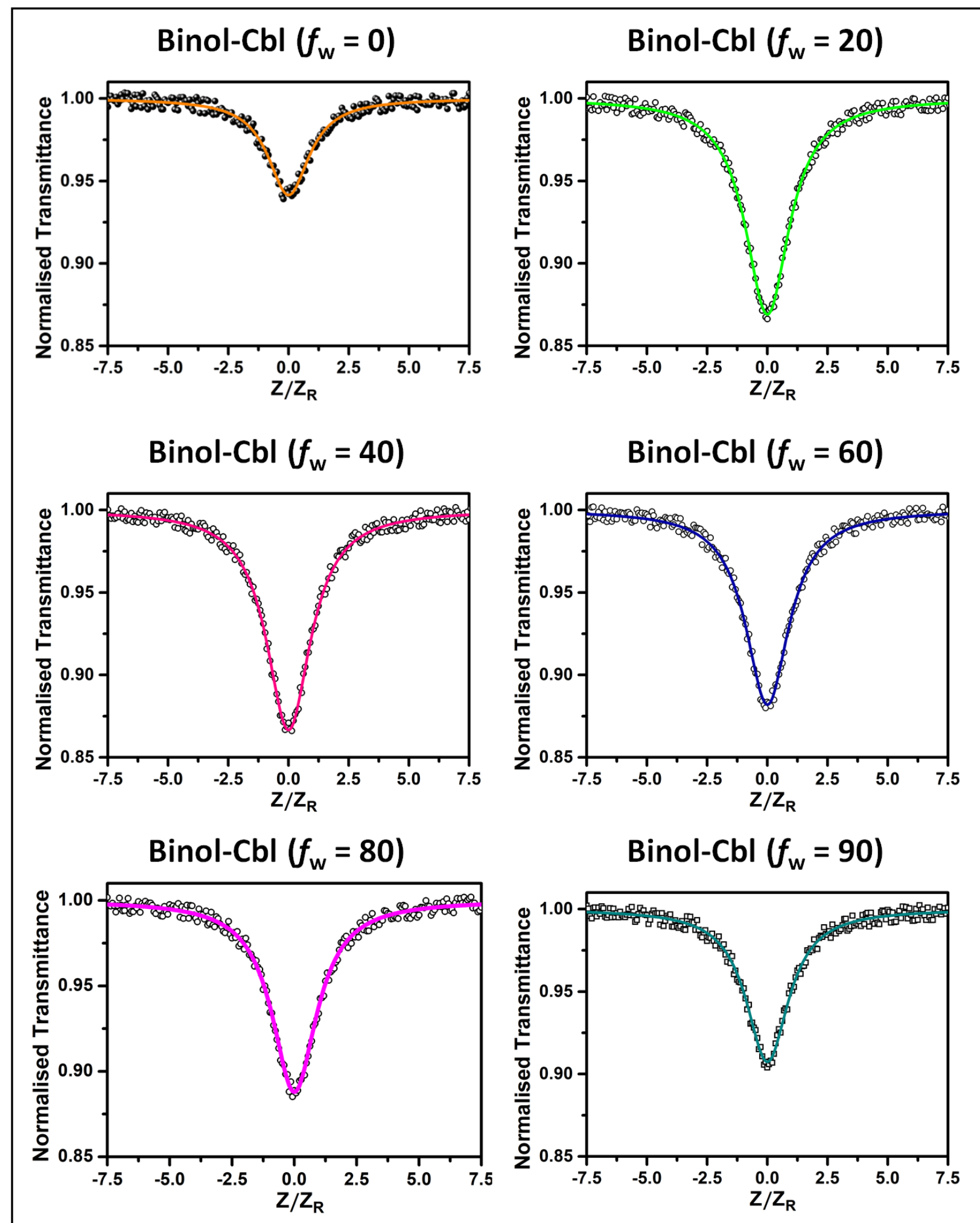

Figure S11: Open aperture (OA) Z-scan data of Binol-Cbl at $800 \mathrm{~nm}$ in DMSO / buffer (pH - 7.4) binary mixture with varying fw. The solid line represents theoretical fitting by Eq. (1). 


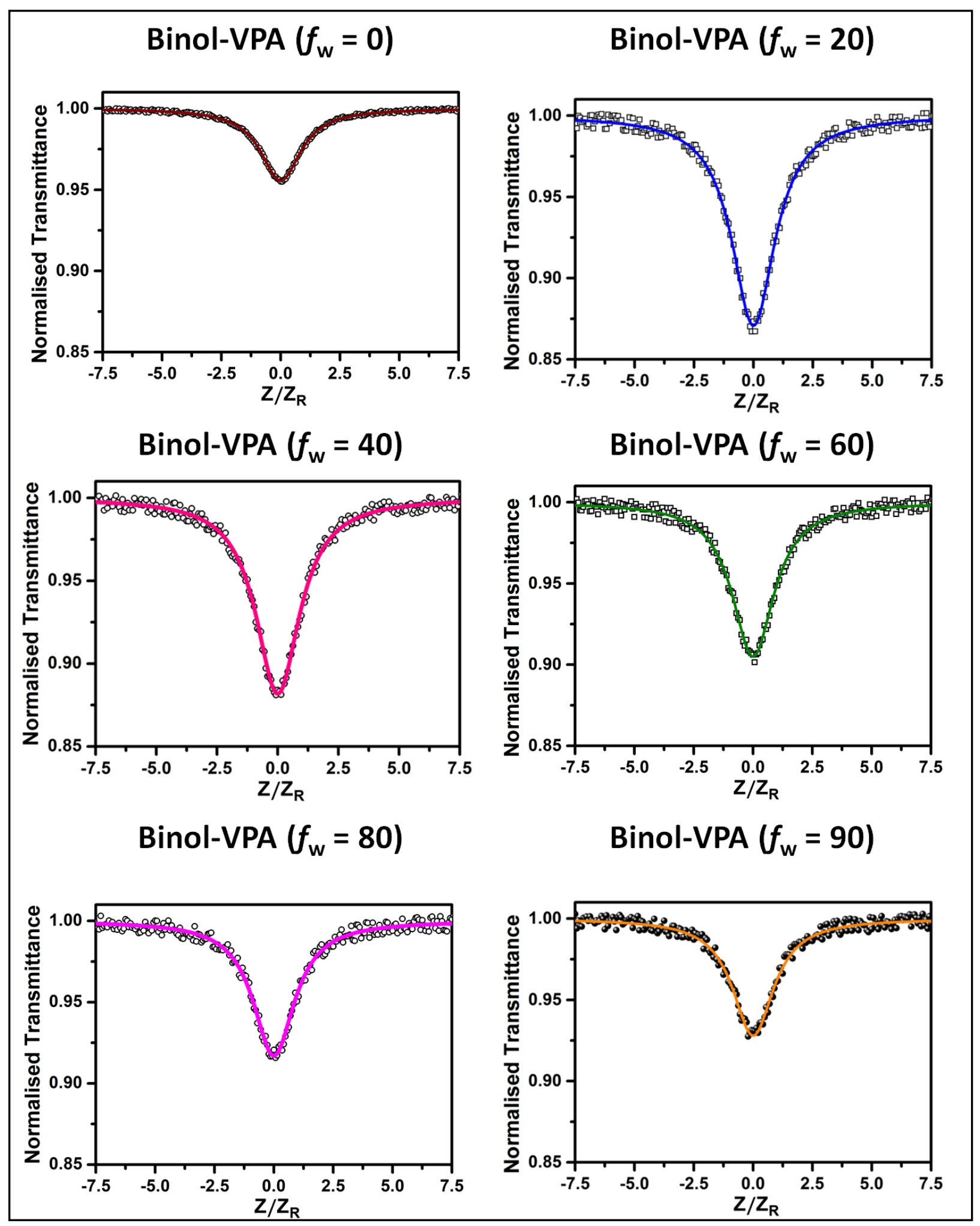

Figure S12: Open aperture (OA) Z-scan data of Binol-Cbl at $800 \mathrm{~nm}$ in DMSO / buffer (pH - 7.4) binary mixture with varying fw. The solid line represents theoretical fitting by Eq. (1). 
8. Stability of prodrugs:

\begin{tabular}{|l|l|l|l|l|}
\hline \multicolumn{2}{|c|}{} & \multicolumn{1}{|c|}{ Biological medium } & \multicolumn{2}{c|}{ Different $\mathrm{pHs}$} \\
\hline Prodrug & Time & $\begin{array}{l}10 \% \text { fetal bovine serum } \\
\mathrm{pH}=7.4\end{array}$ & $\mathrm{pH}=5$ & $\mathrm{pH}=8$ \\
\hline Binol-VPA & 7 days & $<1$ & $<2$ & 3 \\
\hline Binol-Cbl & 7 days & 4 & 5 & 5 \\
\hline
\end{tabular}

(a) As examined by RP-HPLC.

Table S3: Percentage of decomposition under dark condition ${ }^{\mathrm{a}}$ of Binol-VPA and Binol-Cbl in biological medium and in different $\mathrm{pHs}$ at $37^{\circ} \mathrm{C}$. 


\section{Procedure for the quantification of the released drug from Binol-Cbl and Binol-VPA:}

\subsection{Photolysis of Binol-Cbl and Binol-VPA:}

To check the ability of both the conjugates, Binol-Cbl and Binol-VPA as a photoresponsive drug delivery system, a $30 \mathrm{~mL}\left(1 \times 10^{-4} \mathrm{M}\right)$ solution of each conjugates in DMSO/PBS buffer of $\mathrm{pH} 7.4$ $(2: 8)$ was taken and degassed prior to expose to a medium pressure mercury lamp (125 W) as the source of light $(\lambda \geq 410 \mathrm{~nm})$ using $1(\mathrm{M})$ aqueous solution of $\mathrm{NaNO}_{2} \mathrm{UV}$ cut-off filter.

The quantification of the released drug from both the conjugates, Binol-Cbl and Binol-VPA with respect to time was carried out by exposing the solution of both the conjugates individually to the visible light in a regular interval of time (Figure S13, S14). An aliquot of $25 \mu \mathrm{L}$ was injected in HPLC in each interval. The released drug was quantified from the HPLC peak area in comparison with injected authentic sample.

To demonstrate the precise control over the drug delivery, the solution was exposed to light and dark condition, periodically (Figure S15b). Aliquots of $25 \mu \mathrm{L}$ were injected in each case in the HPLC. The released drug was quantified from the HPLC peak area in comparison with the injected authentic sample.

Individual compounds are characterized by HRMS spectroscopy (Figure S17 - S19). 


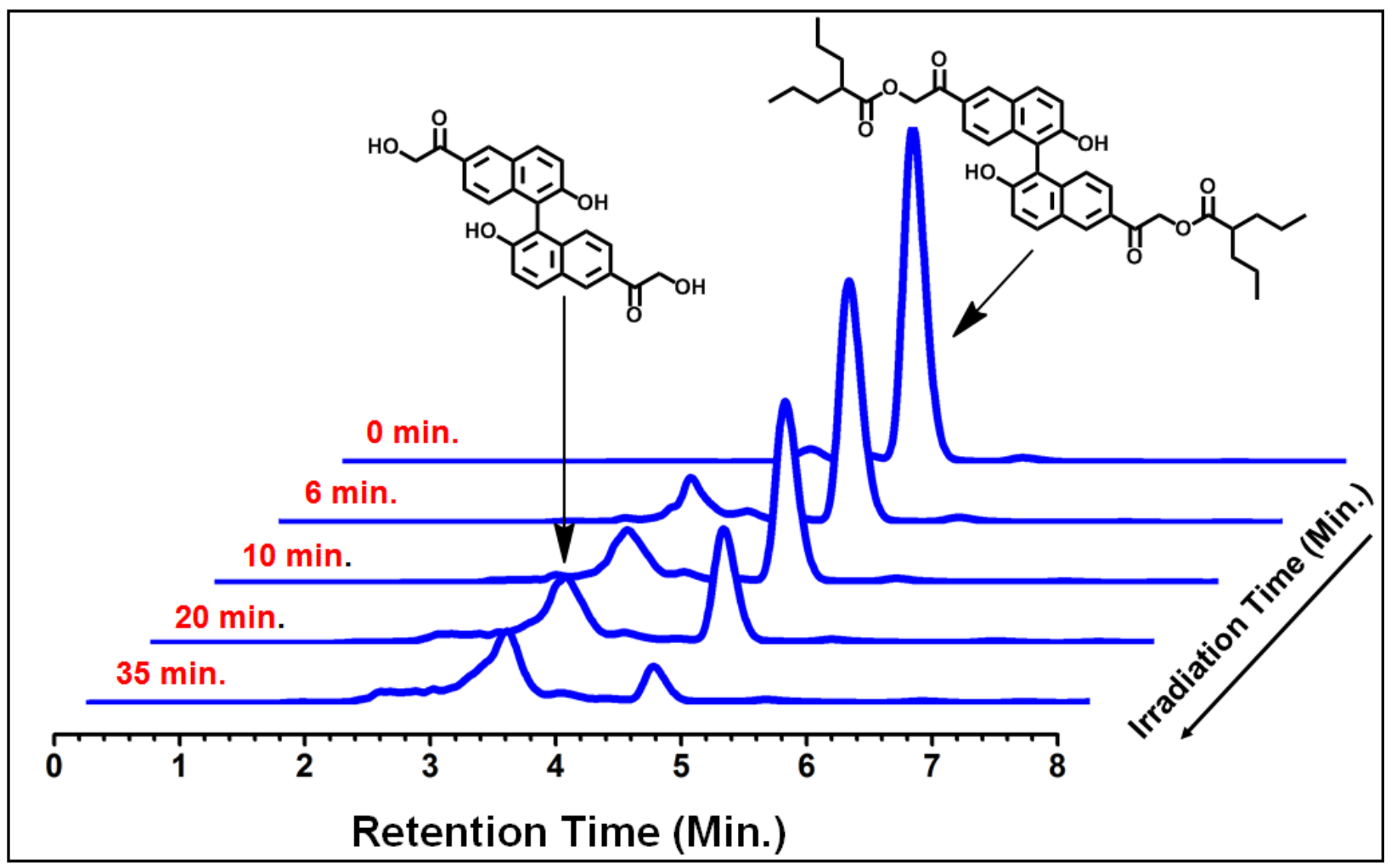

Figure S13: HPLC overlay chromatogram of a $1 \times 10^{-4} \mathrm{M}$ solution of Binol-VPA at different time intervals of light irradiation ( $\geq 410 \mathrm{~nm}$ ) 


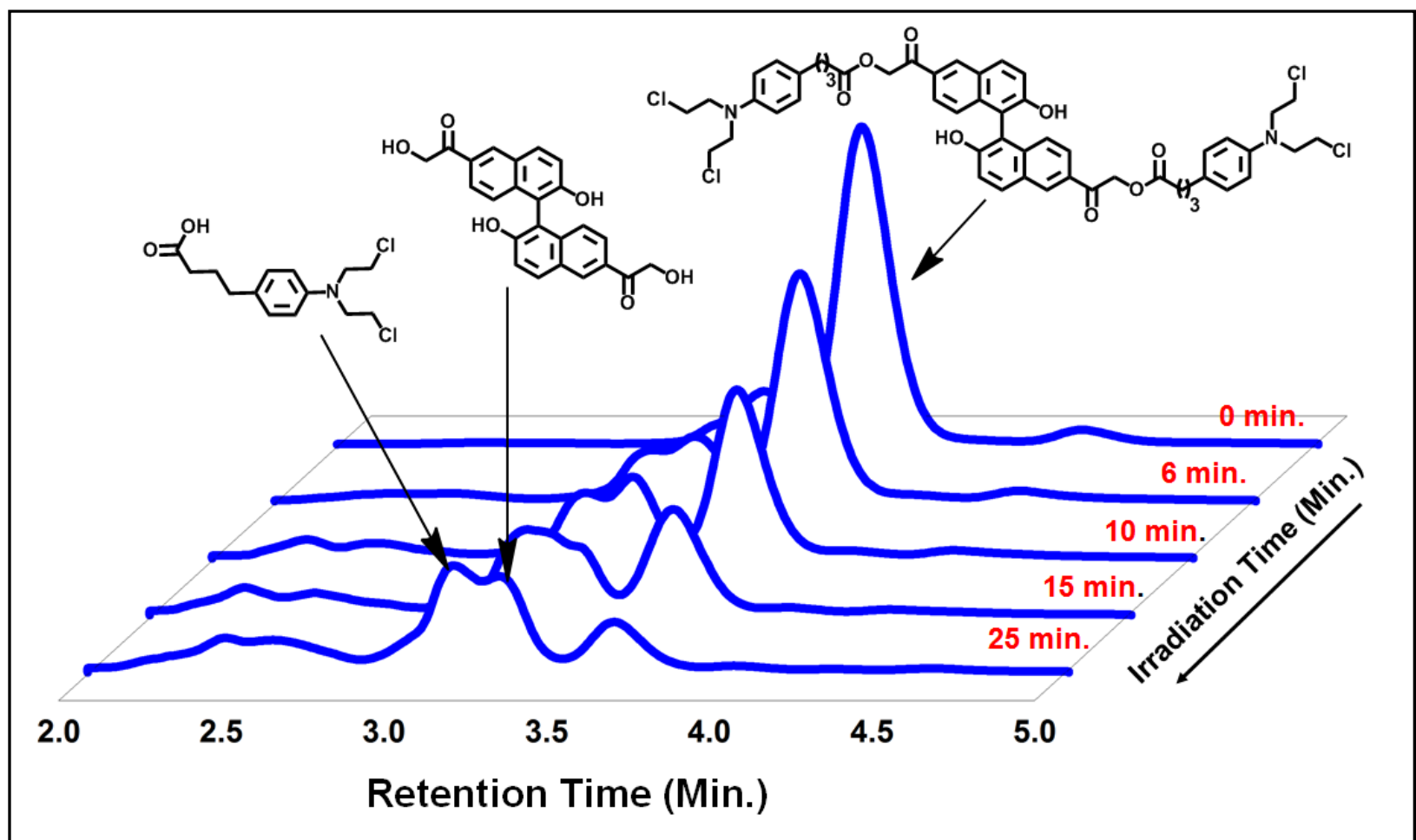

Figure S14: HPLC overlay chromatogram of a $1 \times 10^{-4} \mathrm{M}$ solution of Binol-Cbl at different time intervals of light irradiation ( $\geq 410 \mathrm{~nm})$. 


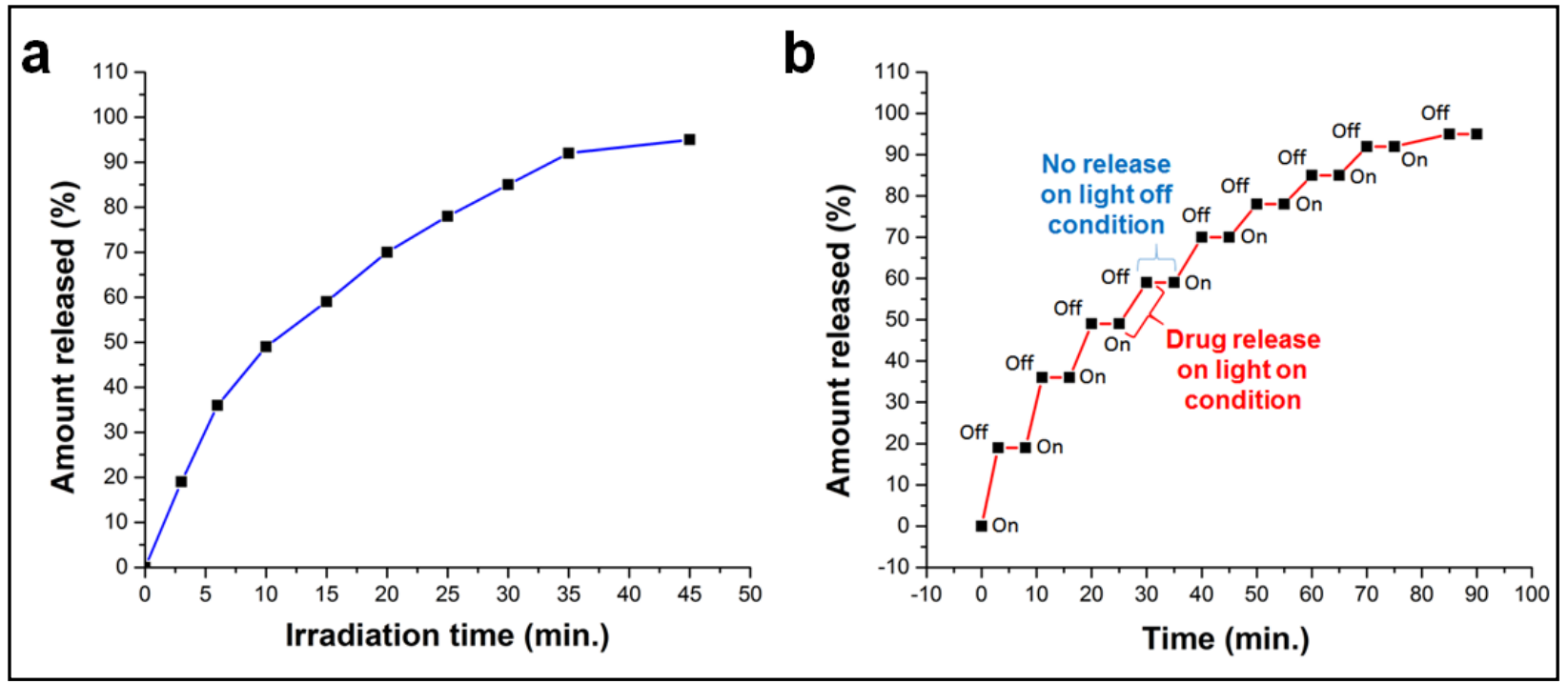

Figure S15: (a) The amount of Binol-VPA uncaged on photolysis ( $\geq 410 \mathrm{~nm}$ ) at different time intervals. (b) Photouncaging of Binol-VPA under light and dark conditions. "On" and "Off" implies the switching on and off of the light source, respectively.

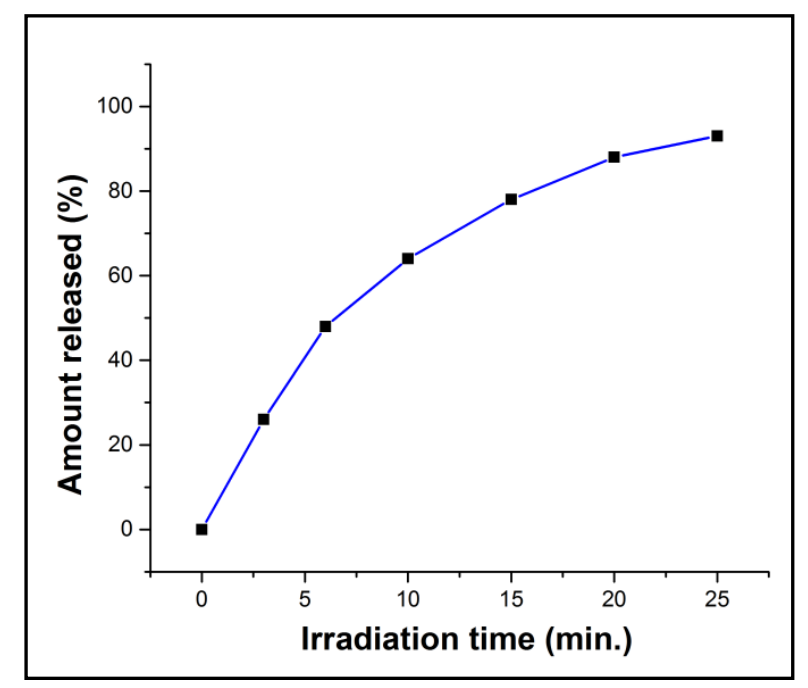

Figure S16: (a) The amount of Binol-Cbl uncaged on photolysis ( $\geq 410 \mathrm{~nm}$ ) at different time intervals. 
Sample Information

Name

Sample ID

Instrument

MS Type

Inj, Vol. (ul)

Position

Plate Pos.

Operator

Sample Chromatograms

$\times 10^{8}$ + + TIC SCan PS_BINOL_VPA_30M_POS_01,d

$1.2-$
$1-$
$0.8-$
$0,6-$
$0,4-$
$0,2-$

0

0.1
Data File Path

Acq, Time (Local)

Method Path (Acq)

Version (Acq SW)

IRM Status

Method Path (DA)

Target Source Path

Result Summary
D:MassHunter|Data|JAN 2020123-01-20201PS_BINOL_VPA_30M_POS_01,d

1/23/2020 11:07:42 AM (UTC+05:30)

D:IMasshunterymethods\TRAINING MMS SCAN POS_01,m

6200 series TOF/6500 series Q-TOF B,09,00 (B9044,1 SP1)

Success

D:MassHunterYMethodSITARGETED ANALYYSIS REPORTING_01.m

1 qualified (1 targets)
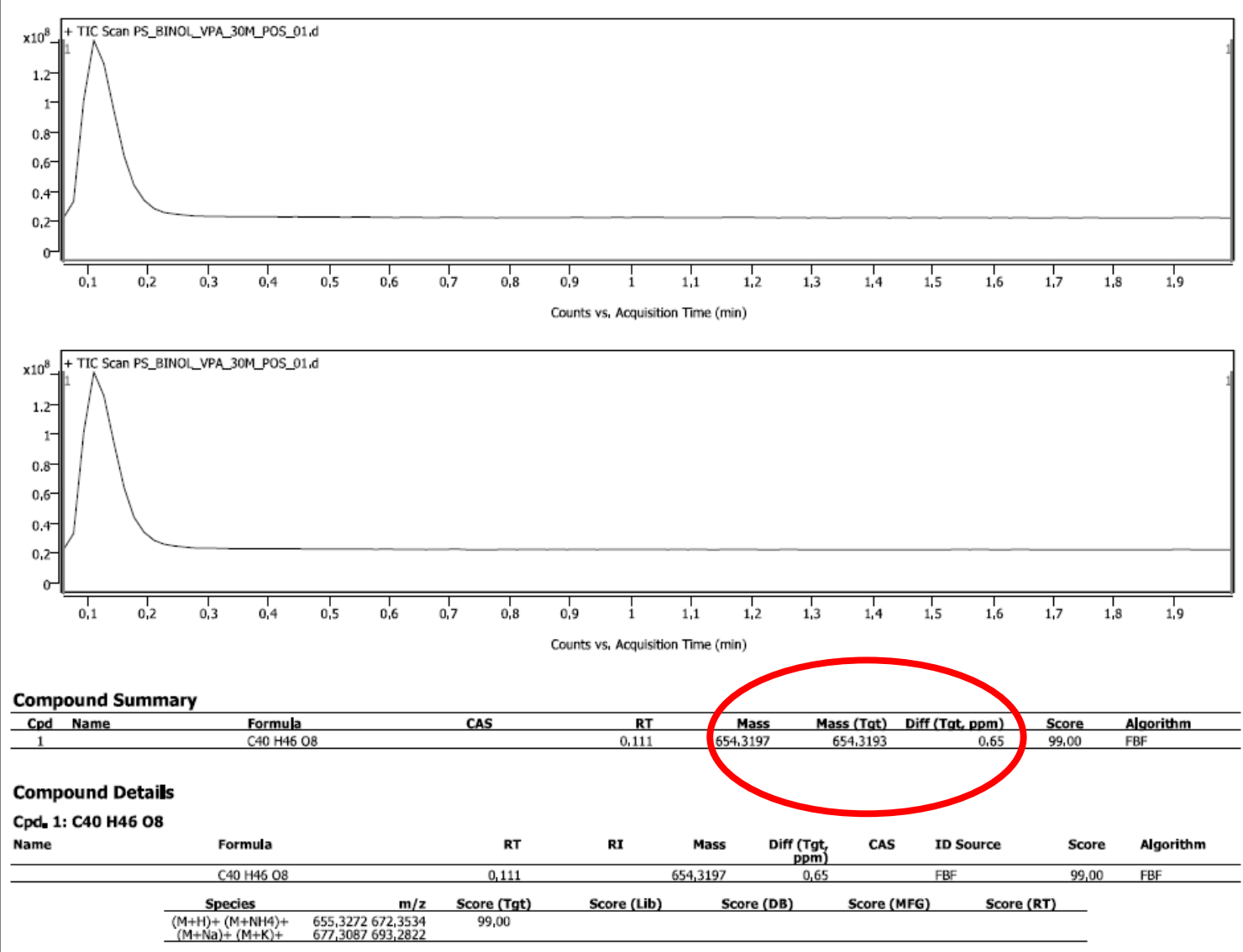

Figure S17: HRMS spectrum of uncaged Valproic acid from an irradiated solution of Binol-VPA. 


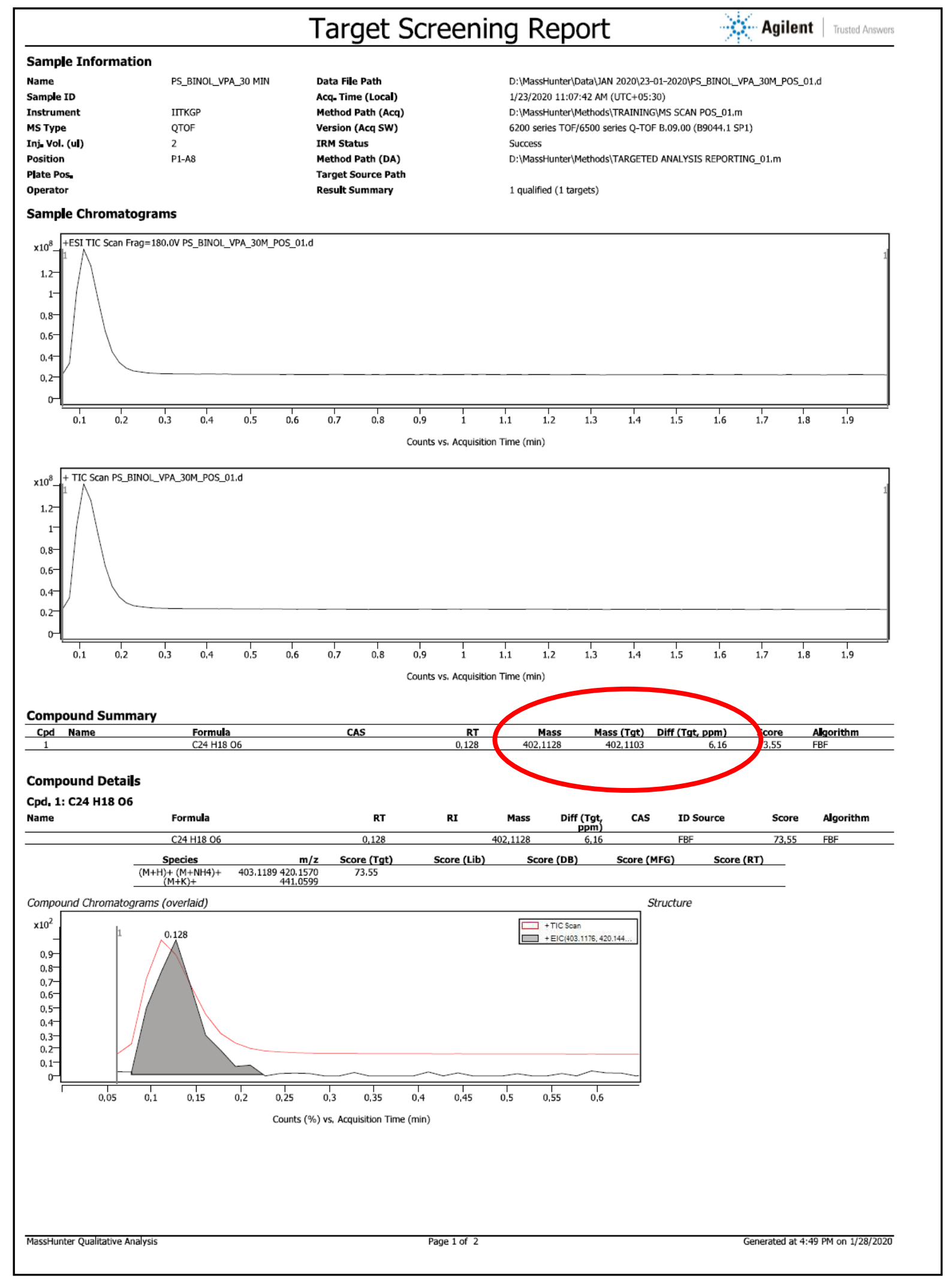

Figure S18: HRMS spectrum of photoproduct from an irradiated solution of Binol-VPA. 
Target Screening Report

\section{Sample Information}

Name

Sample ID

Instrument

MS Type

Inj, Vol. (ul)

Position

Plate Pos.

Operator

Sample Chromatograms

$\times 10^{8}+$ + TIC Scan PS_BINOL_VPA_30M_POS_01,d

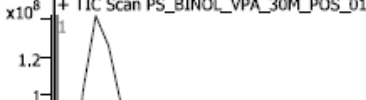

1.2-

$0,4-1$

-

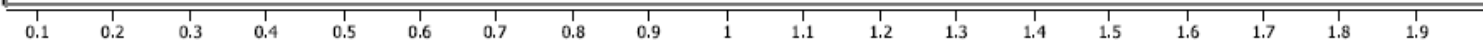

Counts vs, Acquisition Time (min)

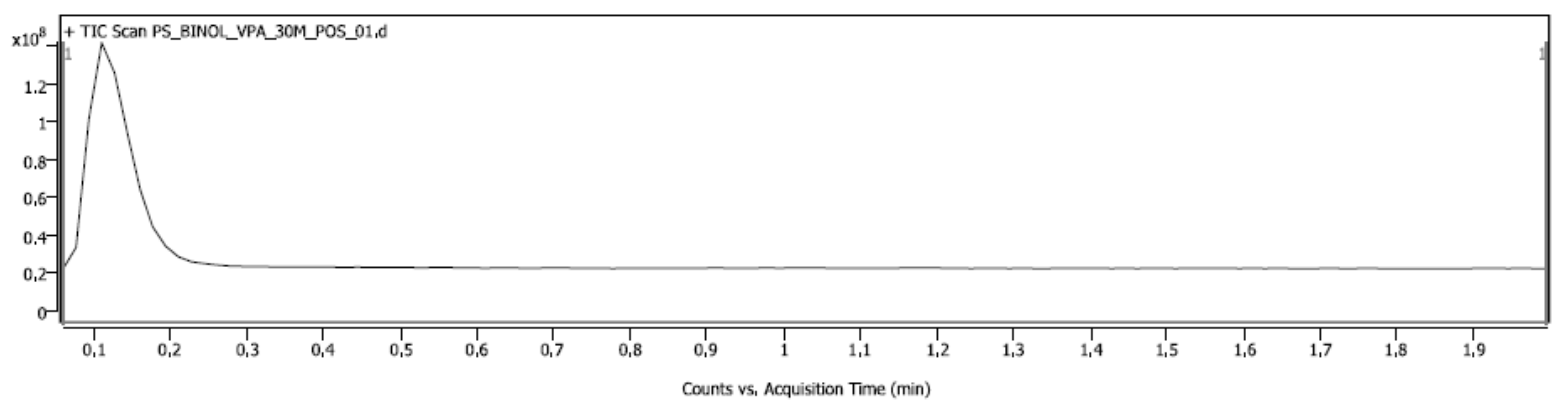

$\times 10^{8}$ - + TIC Scan PS_BINOL_VPA_30M_POS_01,d

$1.2-1$
1
$0.8-1$
$0.6-1$
$0.4-1$
$0.2-1$

=

0,1

$\times 10^{8}+$ + TIC Scan PS_BINOL_VPA_30M_POS_01.d

$\times 10^{8}$
1.2
1
$0.8-$
$0.6-$
$0.4-$
$0.2-$

-

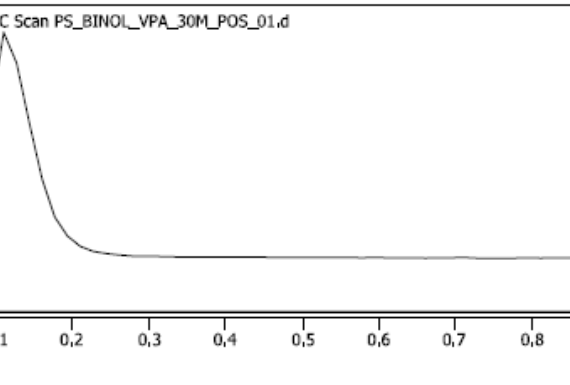

Target Source Path

D:IMassHunter|Data\AN 2020123-01-2020ไPS_BINOL_VPA_30M_POS_01,d

1/23/2020 11:07:42 AM (UTC+05:30)

D:MassHunterVMethods\TRAININGIMS SCAN POS_01,m

6200 series TOF/6500 series Q-TOF B,09,00 (B9044,1 SP1)

Success

D:IMassHunter|Methods\TARGETED ANALYSIS REPORTING_01.m

1 qualified (1 targets)

Counts vs, Acquisition Time (min) 


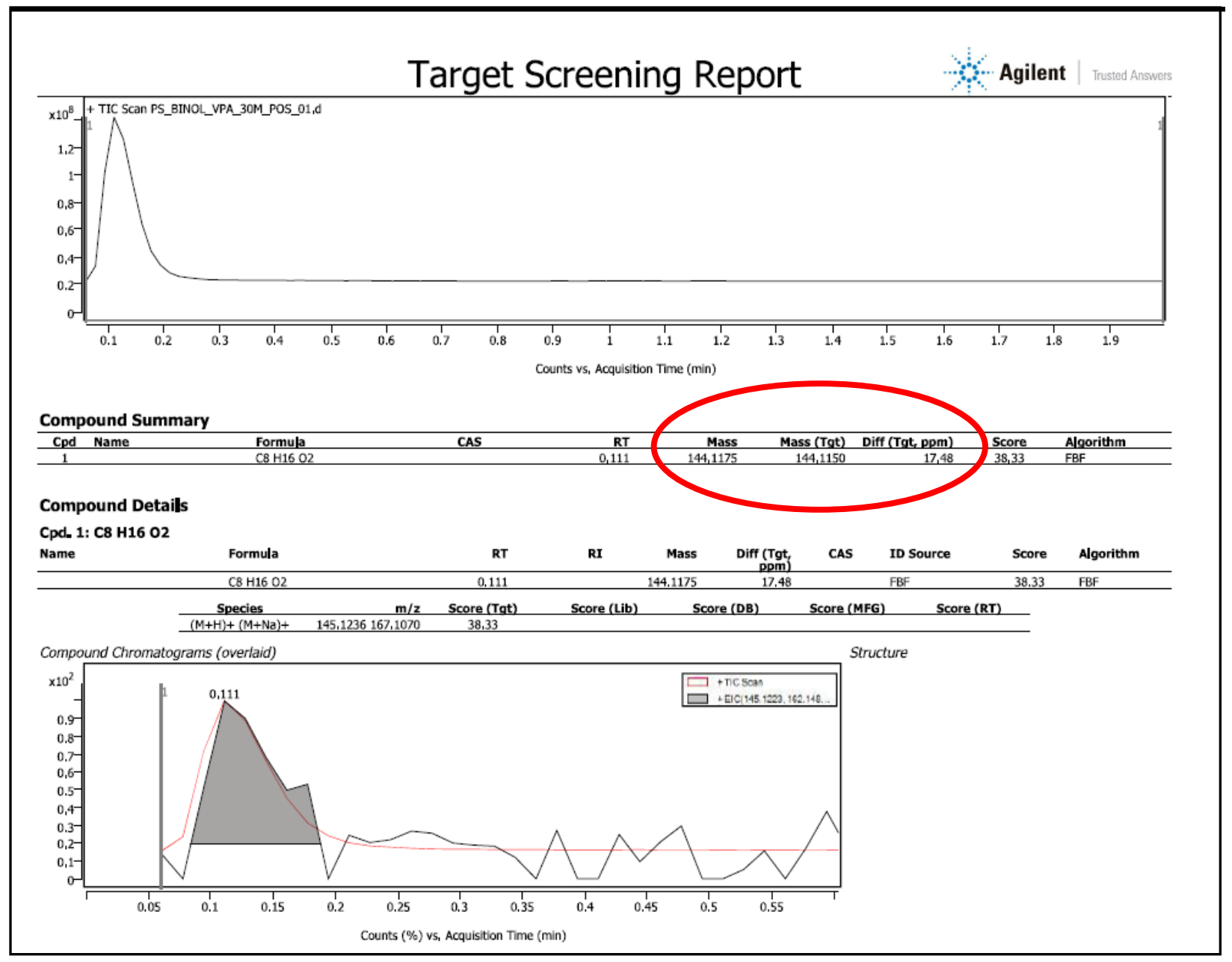

Figure S19: HRMS spectrum of uncaged Valproic acid from an irradiated solution of Binol-VPA. 
10. Overlaid emission spectra of Binol-VPA (before and after photolysis) and photoproduct:

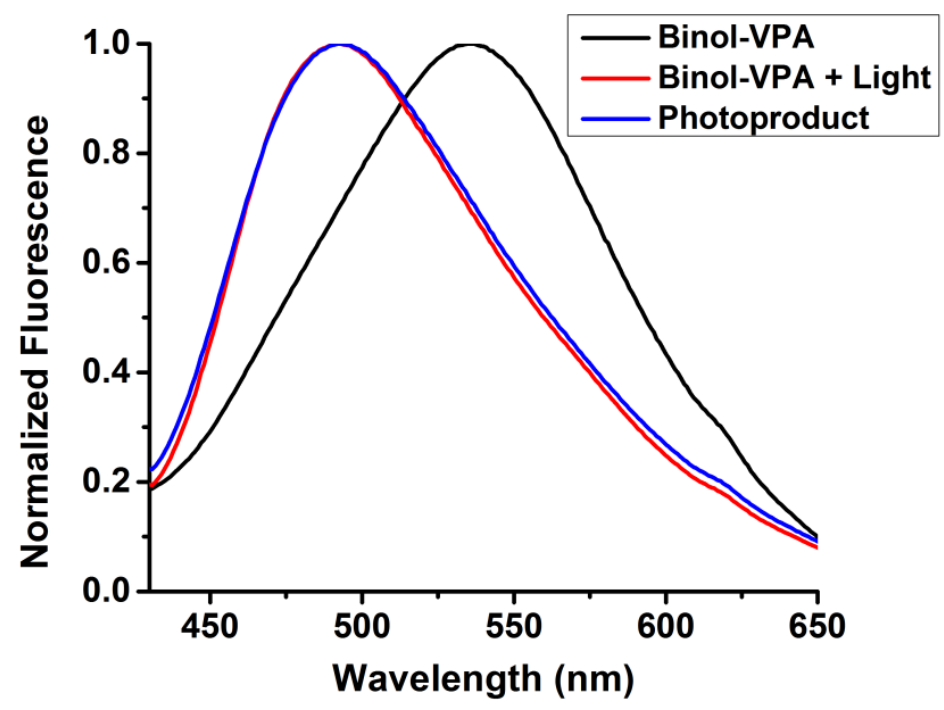

Figure S20: Normalized fluorescent spectra of the photoproduct and Binol-VPA before and after light irradiation.

\section{Measurement of fluorescence quantum yields:}

The fluorescence quantum yield (QY) of Binol-VPA and Binol-Cbl were determined by reference point method. ${ }^{3}$ Quinine sulphate in $0.1 \mathrm{M} \mathrm{H}_{2} \mathrm{SO}_{4}$ (literature quantum yield: 0.547 ) was used as a standard sample to calculate the QY. Both the conjugates were dissolved in DMSO/PBS buffer of $\mathrm{pH} 7.4(2: 8)$. The absorbance values of the solutions at the excitation wavelength were measured with UV-Vis spectrophotometer. Photoluminescence (PL) emission spectra were recorded by Hitachi F-7000 fluorescence spectrophotometer at an excitation wavelength of $350 \mathrm{~nm}$ and 380 for quinine sulphate and both the conjugates respectively.

$$
\frac{(\Phi) s}{(\Phi) r}=\frac{(A) s}{(A) r} X \frac{(A b s) r}{(A b s) s} X \frac{(\eta) s}{(\eta) r}
$$

Where $\Phi$ represents quantum yield, Abs represents absorbance, A represents area under the fluorescence curve, $\boldsymbol{\eta}$ is refractive index of the medium, $s$ and rdenote the corresponding parameters for the sample and reference, respectively. 


\begin{tabular}{|c|c|}
\hline compounds & Fluorescent quantum yield $\left(\varphi_{\mathrm{f}}\right)$ \\
\hline Binol-VPA & 0.29 \\
\hline Binol-Cbl & 0.31 \\
\hline Photoproduct & 0.23 \\
\hline
\end{tabular}

Table S4: Fluorescence quantum yields of Binol-VPA and Binol-Cbl and the photoproduct in 2:8 DMSO/PBS solvent system.

\section{Determination of incident photon flux $\left(I_{0}\right)$ of the UV lamp by potassium ferrioxalate actinometry:}

Potassium ferrioxalate actinometry was used for the determination of incident photon flux $\left(I_{0}\right)$ of the UV lamp used for irradiation. Solution of potassium ferrioxalate, 1, 10-phenanthroline and the buffer solution were prepared following the literature procedure. ${ }^{4,5}$

Solution $(0.006 \mathrm{M})$ of potassium ferrioxalate was irradiated using $125 \mathrm{~W}$ medium pressure Hg lamp as UV light source ( $\geq 365 \mathrm{~nm}$ ) and $1 \mathrm{M} \mathrm{CuSO}_{4}$ solution as UV cut-off filter. At regular interval of time ( $3 \mathrm{~min}$ ), $1 \mathrm{ml}$ of the aliquots was taken out and to it $3 \mathrm{ml}$ of 1,10 phenanthroline solution and $2 \mathrm{ml}$ of the buffer solution were added and the whole solution was kept in dark for $30 \mathrm{~min}$. The absorbance of red phenanthroline-ferrous complex formed was then measured spectrophotometrically at $510 \mathrm{~nm}$. The amount of $\mathrm{Fe}^{2+}$ ion was determined from the calibration graph. The calibration graph was plotted by measuring the absorbance of phenanthroline-ferrous complex at several known concentration of $\mathrm{Fe}^{2+}$ ion in dark. From the slope of the graph the molar absorptivity of the phenanthroline-ferrous complex was calculated at $510 \mathrm{~nm}$, which is found to be similar to reported value. ${ }^{6}$ Using the known quantum yield for potassium ferrioxalate actinometer at $363.8 \mathrm{~nm}$, the number of $\mathrm{Fe}^{2+}$ ion formed during photolysis and the fraction of light absorbed by the actinometer, the incident photon flux ( $\left.\mathrm{I}_{0}\right)$ at $365 \mathrm{~nm}$ of the $125 \mathrm{~W} \mathrm{Hg}$ lamp was determined as $1.55 \times 10^{17}$ photons $\mathrm{s}^{-1} \mathrm{~cm}^{-2}$.

Similarly we were determined the incident photon flux ( $\left.\mathrm{I}_{0}\right)$ at $410 \mathrm{~nm}$ of the $125 \mathrm{~W} \mathrm{Hg}$ lamp with $1 \mathrm{M} \mathrm{NaNO}_{2}$ solution as UV cut-off filter, is $2.886 \times 10^{16}$ photons $\mathrm{s}^{-1} \mathrm{~cm}^{-2}{ }^{7}$ 
13. Photochemical quantum yield determination for both the conjugates, Binol-Cbl and BinolVPA:

$30 \mathrm{~mL}$ solution of both the conjugates, Binol-Cbl and Binol-VPA of $1 \times 10^{-4} \mathrm{M}$ were prepared in DMSO/PBS buffer of pH 7.4 (2:8). Nitrogen was passed throughout the solution for $30 \mathrm{~min}$ and irradiated with a $125 \mathrm{~W}$ medium pressure $\mathrm{Hg}$ lamp as light source ( $\geq 410 \mathrm{~nm}$ ) using $1 \mathrm{M} \mathrm{NaNO}_{2}$ solution as UV cut-off filter. At regular interval of time, $20 \mu l$ of the aliquots was taken and analyzed by RP-HPLC using mobile phase acetonitrile, at a flow rate of $1 \mathrm{~mL} / \mathrm{min}$ (detection: UV $270 \mathrm{~nm}$ ). Peak areas were determined by RP-HPLC, which indicated gradual decrease of the caged compound with time, and the average of three runs. The reaction was followed until the consumption of the ester is less than $10 \%$ of the initial area. Based on HPLC data for caged compound, the natural logarithm of the concentration of caged compound (InC) (from HPLC peak area) versus irradiation time was plotted. We observed an exponential correlation for the disappearance of the caged compounds which suggested a first order reaction.

Further, the quantum yield for the photolysis of caged compound was calculated using equation (1)

$$
(\Phi) C G=(\Phi) \text { act } \times[(\mathrm{kp}) \mathrm{CG} /(\mathrm{kp}) \mathrm{act}] \times[\mathrm{Fact} / \mathrm{FCG}]
$$

Where, the subscript ' $C G$ ' and 'act' denote caged compound and actinometer, respectively. $\Phi$ is the relative photolysis quantum yield, $\mathrm{kp}$ is the photolysis rate constant and $\mathrm{F}$ is the fraction of light absorbed. Potassium ferrioxalate was used as an actinometer. ${ }^{5,8}$ 


\begin{tabular}{|c|c|c|}
\hline \multirow{2}{*}{$\begin{array}{c}\text { Irradiation } \\
\text { wavelength }\end{array}$} & $f_{\mathrm{w}}=\mathbf{2 0}$ & $\boldsymbol{f}_{\mathrm{w}}=\mathbf{8 0}$ \\
\cline { 2 - 3 } & & 0.39 \\
\hline $\mathbf{4 1 0}$ & 0.09 & 0.47 \\
\hline $\mathbf{3 6 5}$ & 0.14 & \\
\hline
\end{tabular}

Table S5: Quantum yield $\left(\varphi_{u}\right)$ of Binol-Cbl with different water fraction $\left(f_{w}\right)$ at different irradiation wavelength.

\begin{tabular}{|c|c|c|}
\hline \multirow{2}{*}{$\begin{array}{c}\text { Irradiation } \\
\text { wavelength }\end{array}$} & $f_{\mathrm{w}}=\mathbf{2 0}$ & $f_{\mathrm{w}}=\mathbf{8 0}$ \\
\cline { 2 - 3 } & & 0.34 \\
\hline $\mathbf{4 1 0}$ & 0.085 & 0.39 \\
\hline $\mathbf{3 6 5}$ & 0.14 & $\left.\boldsymbol{c}_{\mathrm{u}}\right)$ of Binol-VPA at different water fraction $\left(f_{\mathrm{w}}\right)$ \\
\hline
\end{tabular}

Table S6: Quantum yield $\left(\varphi_{u}\right)$ of Binol-VPA with different water fraction $\left(f_{\mathrm{w}}\right)$ at different irradiation wavelength. 


\section{Calculation of two-photon uncaging cross-section for Binol-Cbl and Binol-VPA:}

The two-photon uncaging cross-section for Binol-Cbl and Binol-VPA were calculated from the formula, $\delta_{u}=\varphi_{u} \delta_{a}$. The two-photon absorption cross-section for Binol-Cbl and Binol-VPA were given in Table S1\& S2. The quantum yields were enlisted in Table S5 \& S6.

\begin{tabular}{|c|c|c|}
\hline \multirow{2}{*}{ DDS } & \multicolumn{2}{|c|}{ Two-photon uncaging cross-section $\left(\delta_{u}\right)$ at $f_{\mathrm{w}}=20 \%$ water fraction in GM } \\
\cline { 2 - 3 } & $\boldsymbol{\delta a} \times \boldsymbol{\varphi}_{u}=\boldsymbol{\delta}_{u} \boldsymbol{a t} \mathbf{8 1 0} \mathbf{n m}$ & $\delta a \times \boldsymbol{\varphi}_{u}=\boldsymbol{\delta}_{u} a t \mathbf{7 5 0} \mathbf{n m}$ \\
\hline Binol-Cbl & $91 \times 0.09=8$ & $135 \times 0.14=19$ \\
\hline Binol-VPA & $80 \times 0.085=7$ & $103 \times 0.39=15$ \\
\hline
\end{tabular}

Table S7: Two-photon uncaging cross-section $\left(\delta_{u}\right)$ of Binol-Cbl and Binol-VPA were recorded in DMSO/PBS buffer of $\mathrm{pH} 7.4$ at $f_{\mathrm{w}}=20 \%$ water fraction in GM.

\begin{tabular}{|c|c|c|}
\hline \multirow{2}{*}{ DDS } & \multicolumn{2}{|c|}{ Two-photon uncaging cross-section $\left(\delta_{u}\right)$ at $f_{\mathrm{w}}=80 \%$ water fraction in GM } \\
\cline { 2 - 3 } & $\delta a \times \varphi_{u}=\delta_{u} a t 810 \mathrm{~nm}$ & $\delta a \times \varphi_{u}=\delta_{u} a t 750 \mathrm{~nm}$ \\
\hline Binol-Cbl & $86 \times 0.39=34$ & $112 \times 0.47=52$ \\
\hline Binol-VPA & $61 \times 0.34=21$ & $103 \times 0.39=40$ \\
\hline
\end{tabular}

Table S8: Two-photon uncaging cross-section $\left(\delta_{u}\right)$ of Binol-Cbl and Binol-VPA were recorded at its aggregated state in DMSO/PBS buffer of $\mathrm{pH} 7.4$ at $f_{\mathrm{w}}=80 \%$ water fraction in GM. 


\section{Two-photon photolysis:}

$0.5 \mathrm{~mL}\left(1 \times 10^{-4} \mathrm{M}\right)$ solution of both the conjugates in DMSO/PBS buffer of $\mathrm{pH} 7.4(2: 8)$ seperately prepared and degassedd then taken in a $1 \mathrm{~mm}$ quartz cuvette and irradiated with a laser of wavelength $760 \mathrm{~nm}$ with $100 \mathrm{fs}$ pulses at a $80 \mathrm{MHz}$ rate with a $50 \mu \mathrm{m}$ diameter beam spot. A small aliquots $(25 \mu \mathrm{L})$ before and after the photolysis were taken out from the solution for HPLC study. The released drug was quantified from the HPLC peak area in comparison with injected authentic sample. We have found that after $3 \mathrm{~h}$ of photolysis $21 \%$ of Binol-VPA (Figure S21a) and 23\% Binol-Cbl (Figure S21b) got uncaged.
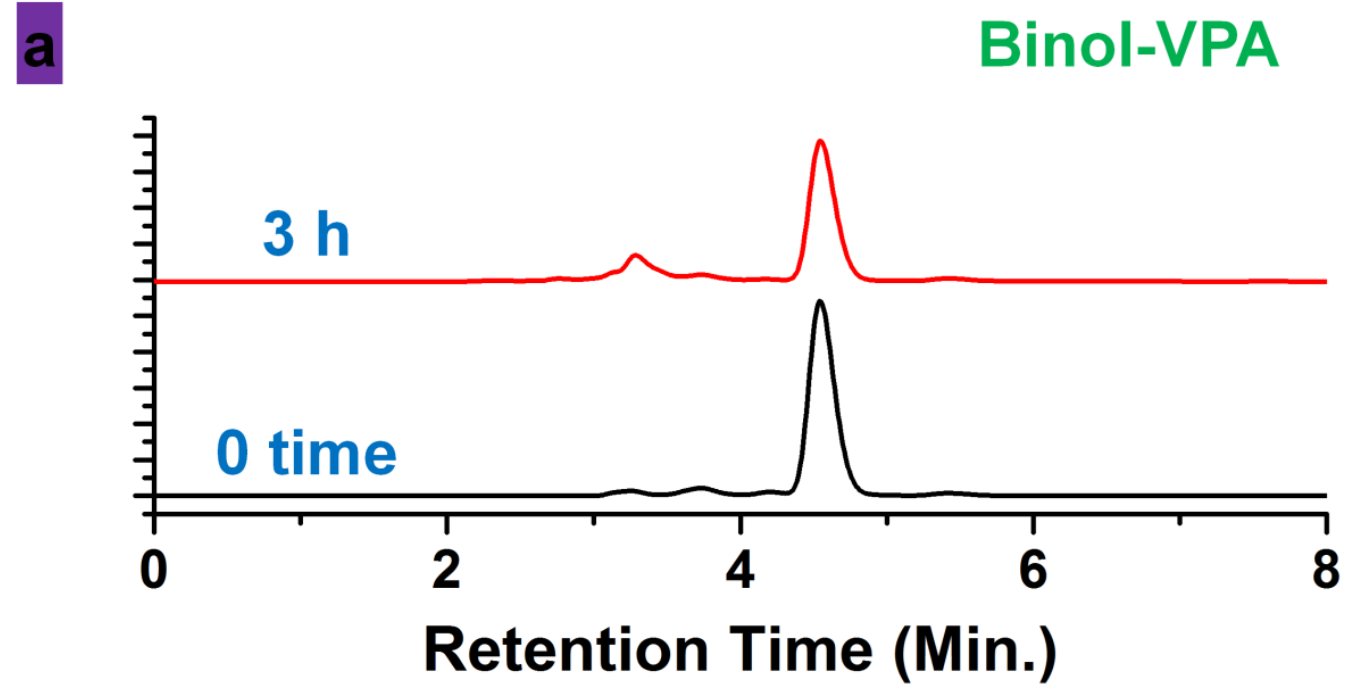

b

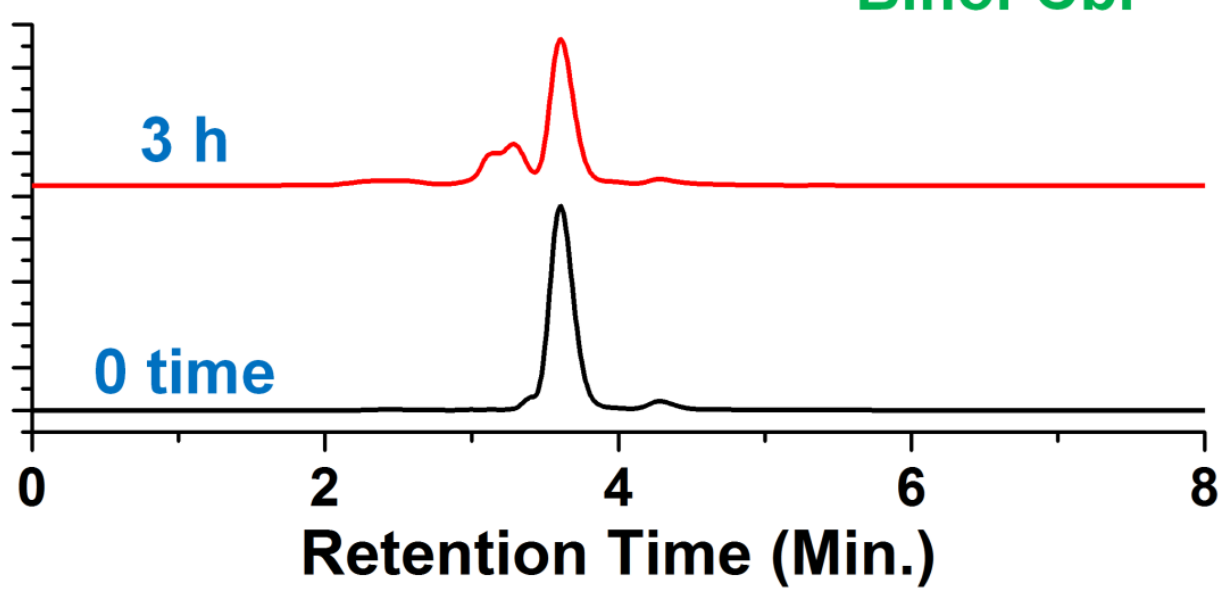

Figure S21: HPLC overlay chromatogram of a $1 \times 10^{-4} \mathrm{M}$ solution of (a) Binol-VPA and (b) Binol$\mathrm{Cbl}$ at different time intervals of light irradiation with Ti:Sapphire laser. 


\section{Mechanism of photorelease:}

First, to demonstrate the mechanism of the photorelease proceeds through Photo-Favorskii reaction, we monitored the photolysis of our DDS by ${ }^{1} \mathrm{H}$ NMR at regular intervals (Figure S22).

\section{1. ${ }^{1} \mathrm{H}$ NMR study of the photouncaging of Binol-VPA:}

$2 \mathrm{mg}$ of Binol-VPA was taken in $0.5 \mathrm{~mL} \mathrm{D}^{6}-\mathrm{DMSO} / \mathrm{D}_{2} \mathrm{O}(1: 1)$ mixed solvent into an NMR tube and was exposed to UV light $(\lambda \geq 410 \mathrm{~nm})$ for a regular interval of time $(0-90 \mathrm{~min}$, time interval $=30$ min). NMR analysis also carried out during these intervals.

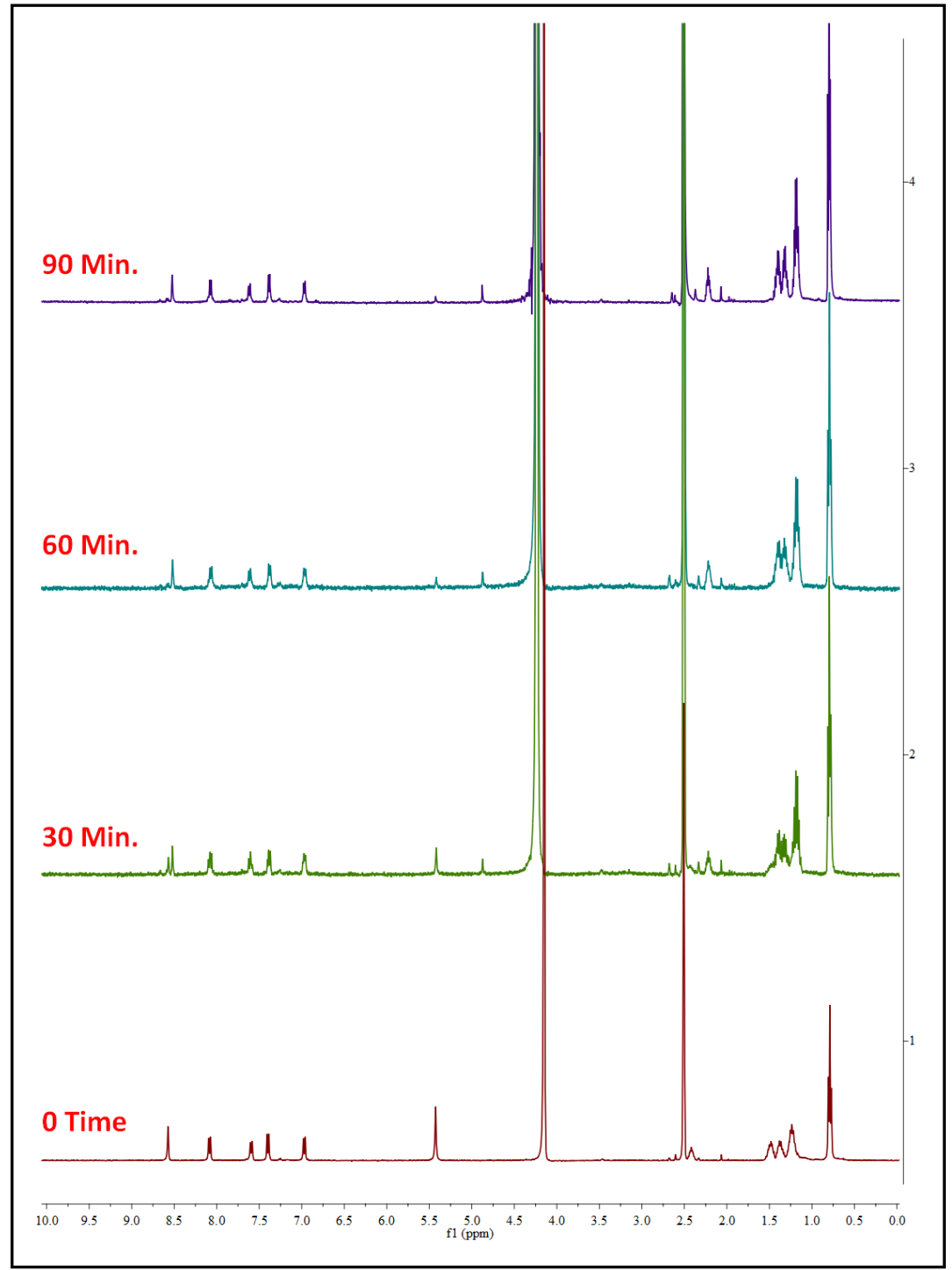

Figure S22: ${ }^{1} \mathrm{H}$ NMR study of Binol-VPA in DMSO- $d^{6} / \mathrm{D}_{2} \mathrm{O}(1: 1)$ during photolysis at regular interval of time (0-90 $\mathrm{min}$, time interval $=30 \mathrm{~min})$. 
Secondly, to check that our photorelease proceeds via the triplet excited state, the photolysis of Binol-VPA was carried out in the presence of the triplet quencher potassium sorbate. ${ }^{6}$ We found that the drug release by Binol-VPA was almost completely arrested. It clearly indicates that the photorelease occurs from the triplet excited state.

\subsection{Quenching studies in the presence of triplet state quencher (potassium sorbate):}

An experiment was performed to ensure whether the photorelease occurs from singlet or triplet state, ${ }^{7}$ in which photolysis of Binol-VPA (1× $\left.10-4 \mathrm{M}\right)$ in DMSO/PBS buffer of pH 7.4 (2:8) was carried out in presence and absence of $200 \mu \mathrm{M}$ of triplet quencher potassium sorbate (PoS). At different time of irradiation $(0,3,6,10,15,20,30,35,45 \mathrm{~min}$.$) aliquots were collected and$ analyzed by RP-HPLC using mobile phase acetronitrile and water (90:10), at a flow rate of $1 \mathrm{~mL} / \mathrm{min}$ (detection: UV $270 \mathrm{~nm}$ ). Peak areas were determined by RP-HPLC. HPLC peaks area of caged compound (from HPLC peak area) versus irradiation time were plotted. The result showed that drug release by Binol-VPA was almost completely arrested in the presence of $200 \mu \mathrm{M}$ PoS, clearly indicating that photorelease occurs from the triplet excited state (Figure S23).

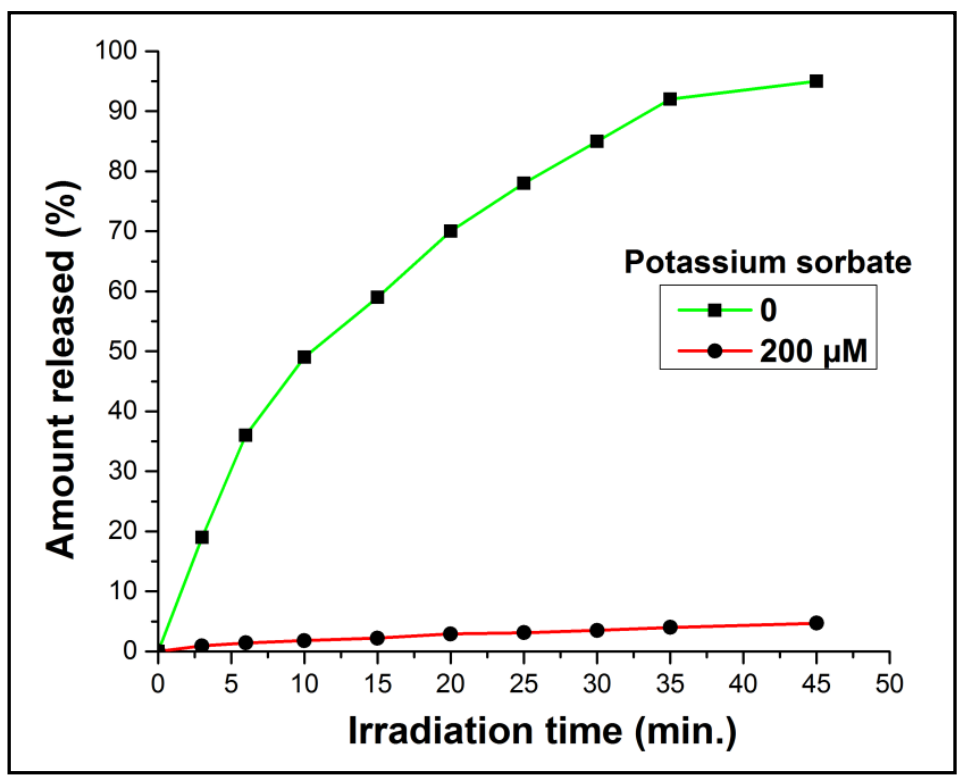

Figure S23: Time course of photolysis of Binol-VPA under irradiation of UV light ( $\geq 410 \mathrm{~nm})$ in the presence of $200 \mu \mathrm{M}$ triplet quencher potassium sorbate (PoS). 
Based on the above experimental results and literature precedence ${ }^{9}$ we proposed a possible mechanism for the photo-uncaging of valproic acid from Binol-VPA in aqueous solution (Scheme S2). Upon irradiation, Binol-VPA is excited to the singlet state then it undergoes efficient intersystem crossing (ISC) to its triplet excited state. From the triplet excited state, it undergoes either homolytic cleavage of the $\mathrm{C}-\mathrm{O}$ bond followed by a single electron trasfer or heterolytic cleavage of the $\mathrm{C}-\mathrm{O}$ bond to directly produce an ion pair intermediate. The ion pair intermediate then reacts with the water molecule to release the drug along with the formation of $\alpha$-cleavage photoproduct.

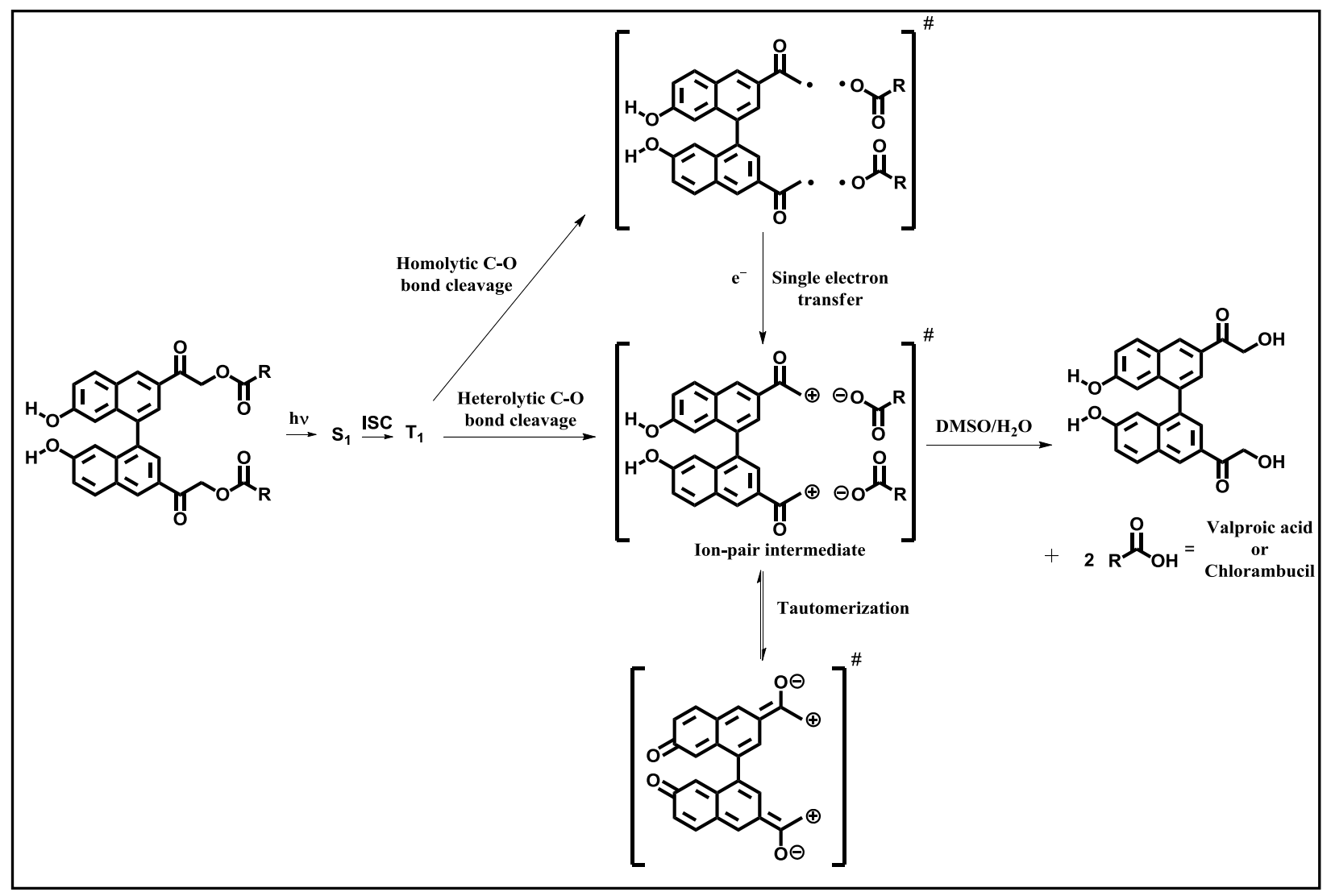

Scheme S2: Possible mechanism of photorelease 
17. Experimental procedure for biological application study with cancerous cell line B16F10 melanoma:

\subsection{In vitro cellular uptake studies of Binol-Cbl in cancerous cell lines B16F10:}

Cellular uptake of Binol-Cbl was studied qualitatively in cancerous cell lines B16F10 melanoma by confocal microscopy. B16F10 cells were seeded $\left(5 \times 10^{4}\right)$ in $35 \mathrm{~mm}$ cover glass with $1 \mathrm{~mL}$ of culture medium (0.02\% DMSO in cell culture medium) for $12 \mathrm{~h}$. Next, the cells were washed with 1X PBS $(3 \times 1 \mathrm{~mL})$ and treated with Binol-Cbl $(10 \mu \mathrm{M})$ for $4 \mathrm{~h}$. Cells were washed with $1 \mathrm{X}$ PBS $(3 \times 1 \mathrm{~mL})$ then fixed with $4 \%$ paraformaldehyde. Next, cells were mounted on coverslip onto glass slide and images were recorded by confocal microscopy (Nikon Ti Eclipse).

\subsection{Intracellular distribution of Binol-CbI in B16F10 cell line}

Intracellular localization of Binol-Cbl by cancerous B16F10 cell line was monitored by confocal laser scanning microscopy (CLSM). The cells were cultured following the standard protocols and were incubated with the Binol-Cbl $(10 \mu \mathrm{M})$ under $5 \% \mathrm{CO}_{2}$ at humified conditions at $37^{\circ} \mathrm{C}$ for $4 \mathrm{~h}$. Cell mitochondria and lysosome were stained separately with myto-tracker red and lyso-tracker red respectively. Then imaging was done by Nikon confocal microscope (Eclipse Ti-E) using the respective filter (Figure S24). 


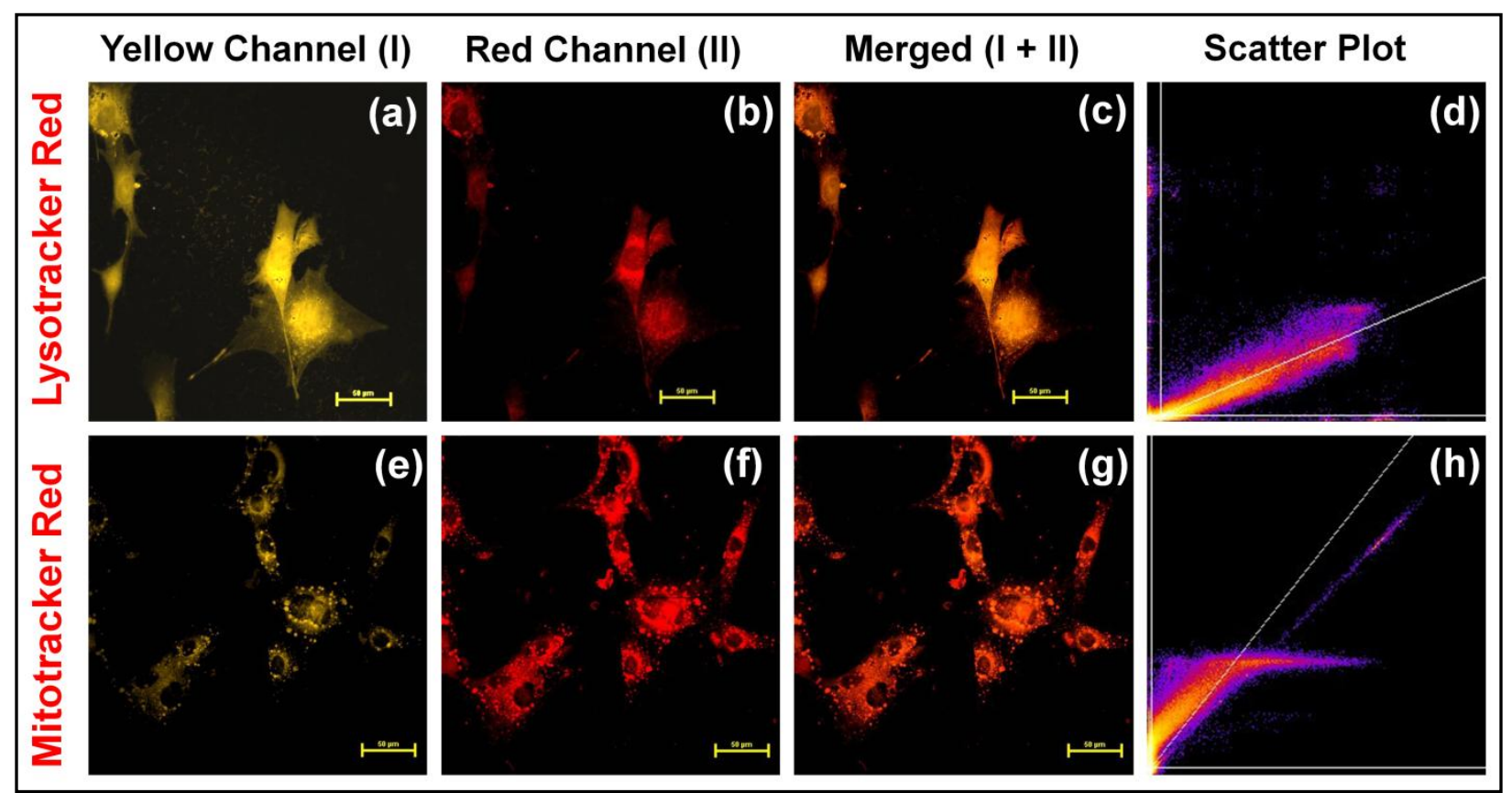

Figure S24: CLSM images of the B16F10 cell lines incubated with Binol-cbl, LTR and MTR: (a,e) yellow channel, $(b, f)$ red channel, $(c, g)$ merged images $(d, h)$ corresponding scatter plots. (d) Concentrated pixels along the diagonals indicate a high degree of colocalization of Binol-cbl and LTR; (h) scattered pixels along the diagonals indicate a lower degree of colocalization of Binol-cbl and MTR. Scale bar: $50 \mu \mathrm{m}$.

\subsection{In Vitro cell viability assay of Binol-DDSs:}

The in vitro cytotoxic studies of Binol-Cbl, Binol-VPA, photoproduct and the free drugs [chlorambucil (Cbl) and valproic acid (VPA)] have been carried out using the MTT (3-(4,5dimethylthiazole-2-yl)-2,5-diphenyltetrazolium bromide) assay. Briefly, cancerous cell line B16F10 was grown in their log phase. Cells were seeded in 96-well plates in Dulbecco's modified Eagle's medium (DMEM) containing $10 \%$ fetal bovine serum (FBS) for $8 \mathrm{~h}$. The cells were incubated with different concentrations (5-40 $\mu \mathrm{M})$ of Binol-Cbl along with two equivalent $\mathrm{Cbl}$ and one equivalent photoproduct in HEPES buffer, at $37^{\circ} \mathrm{C}$ in $5 \% \mathrm{CO}_{2}$ for $72 \mathrm{~h}$. Similarly, another set was treated with different concentrations (25-200 $\mu \mathrm{M})$ of Binol-VPA, along with two equivalent VPA and one equivalent photoproduct. Then cytotoxicity was measured using the MTT assay before and after light irradiation. It was evident from the MTT assay data that both the DDSs 
showed less toxicity to the corresponding cell lines before irradiation, however, an increase in cytotoxicity was observed after irradiation.

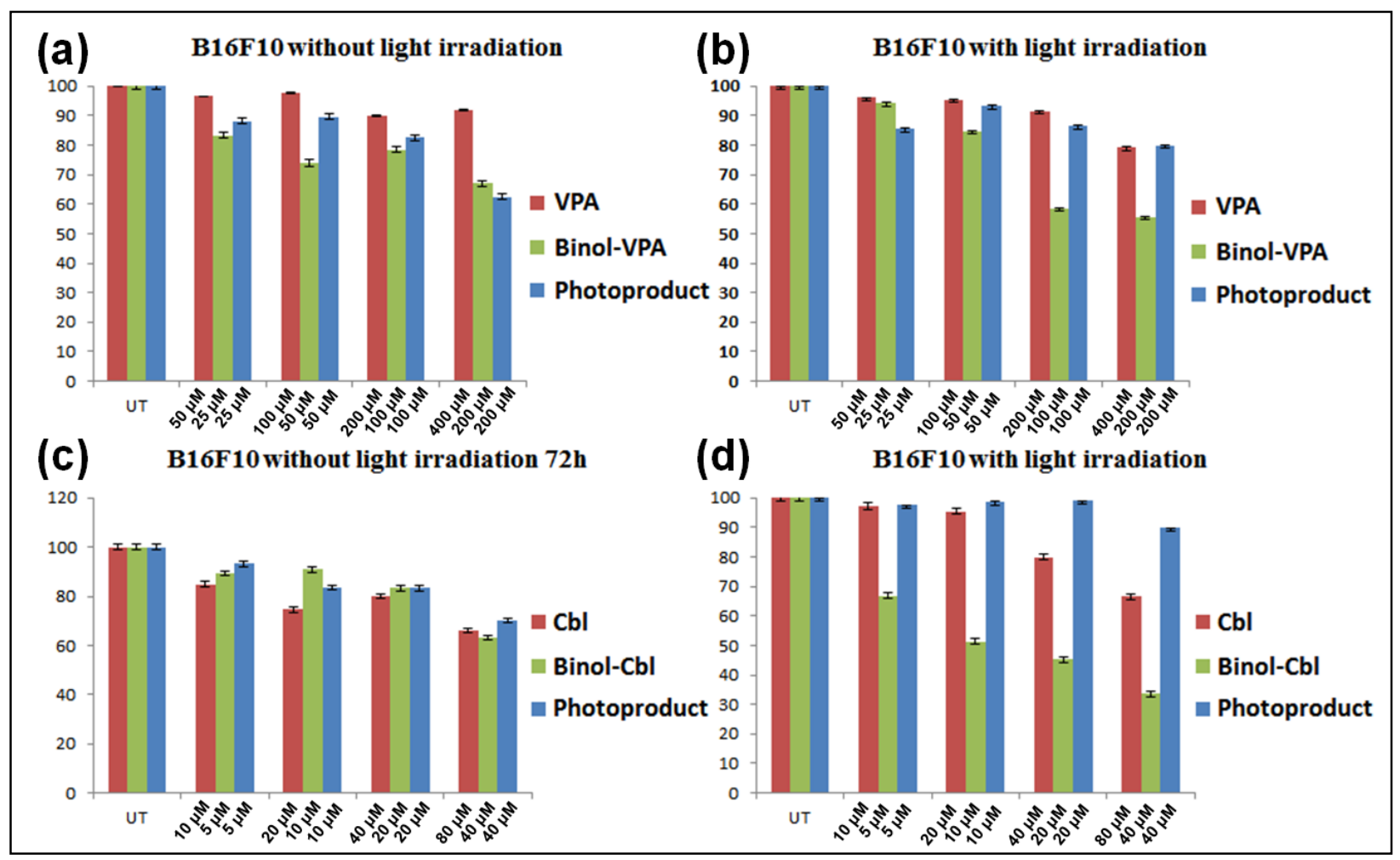

Figure S25: Cell viability assays for Binol-VPA, photoproduct and free valproic acid (VPA) with B16F10 cell line (a) in the dark and (b) after light irradiation for $45 \mathrm{~min}$. Cell viability assays for Binol-Cbl, photoproduct and free chlorambucil (Cbl) with B16F10 cell line (a) in the dark and (b) after light irradiation for $45 \mathrm{~min}$. Data presented are the average of the data obtained in triplicate independent experiments and presented relative to a control. 


\begin{tabular}{|c|c|c|}
\hline \multirow{2}{*}{ Compounds } & \multicolumn{2}{|c|}{ IC $_{50}$ values in $\mu \mathrm{M}$} \\
\cline { 2 - 3 } & Without light irradiation & After light irradiation \\
\hline Free valproic acid & $694( \pm 3.65)$ & $233.4( \pm 6.51)$ \\
\hline Binol-VPA & $492( \pm 4.15)$ & $52.9( \pm 6.56)$ \\
\hline Free chlorambucil & $40.5( \pm 2.07)$ & $19.2( \pm 3.71)$ \\
\hline Binol-Cbl & $21.6( \pm 1.37)$ & $0.7( \pm 0.16)$ \\
\hline Photoproduct & $109.1( \pm 5.07)$ & $106( \pm 2.59)$ \\
\hline
\end{tabular}

Table S9: $\mathrm{IC}_{50}(\mu \mathrm{M})$ values of all the compounds with or without light irradiation. 


\section{Fluorogenic real-time monitoring of drug release study with MCF-7 cells:}

\subsection{Cell lines:}

Human breast carcinoma (MCF-7) was obtained from the National Centre for Cell Science (NCCS), Pune, India. The cell line maintained in dulbecco's modified eagle's medium (DMEM) supplemented with $10 \%$ fetal bovine serum. Cells were cultured at $37{ }^{\circ} \mathrm{C}$ in a $\mathrm{CO}_{2}$ incubator (Thermo Fisher Scientific, USA). S-14

\subsection{Fluorescence microscopy}

Real-time monitoring of drug delivery step for Binol-VPA was recorded with fluorescence microscopy (Figure S26). MCF-7 cells were treated with $100 \mu \mathrm{M}$ Binol-VPA and put aside for $4 \mathrm{~h}$ at $37^{\circ} \mathrm{C}$. After that, cells were irradiated with UV-visible light $(\geq 410 \mathrm{~nm})$ for $45 \mathrm{~min}$. Fluorescent images were captured using a high-performance charge-coupled device (CCD) camera (1X81, Olympus).

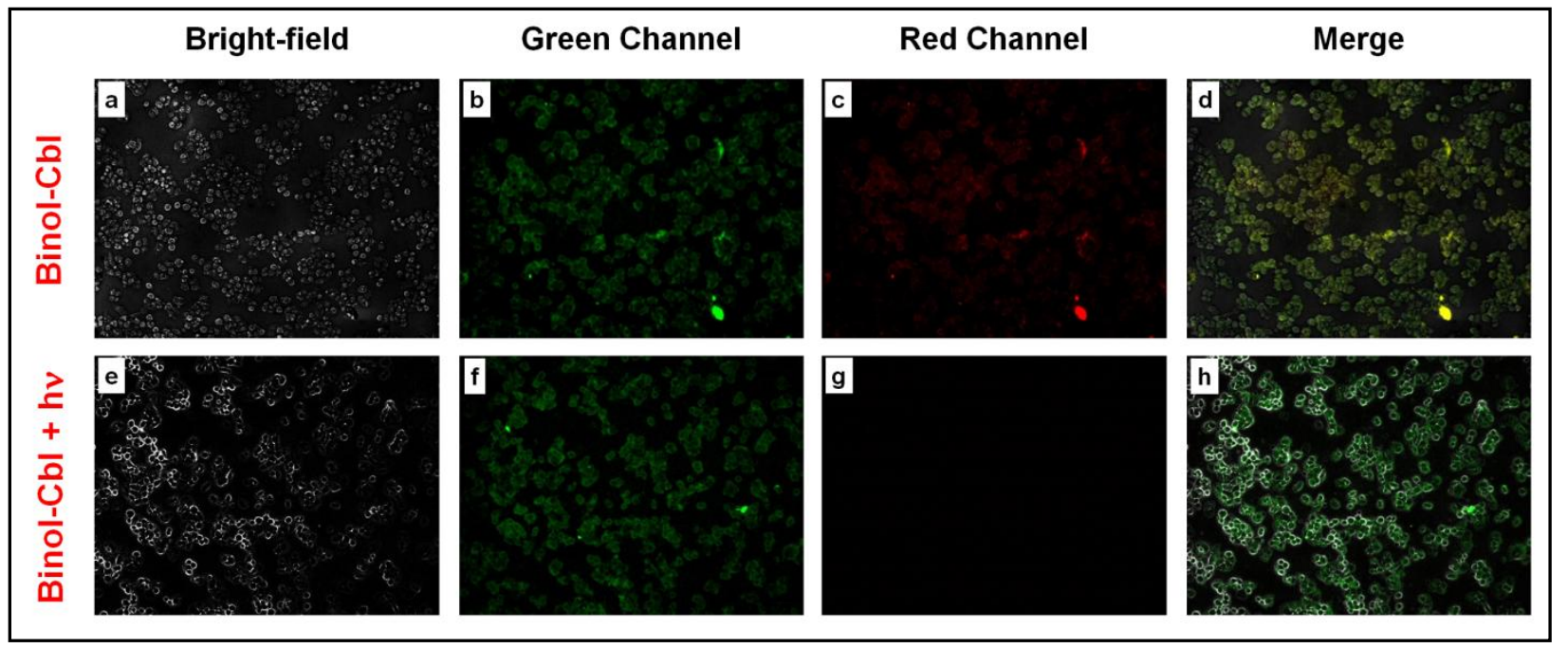

Figure S26: Cellular fluorescence images of MCF-7 cells after cellular uptake study with Binol-Cbl:

(a) bright field image, (b) green channel fluorescence image, (c) red channel fluorescence image

(d) merge of bright field and fluorescence images. Binol-Cbl pretreated cells after irradiation with UV-Visible light ( $\geq 410 \mathrm{~nm}$ ) for $20 \mathrm{~min}$ : (e) bright field image, (f) green channel fluorescence image, (g) red channel fluorescence image (h) merge of bright field and fluorescence images. 


\section{Reference:}

1. Sheik-Bahae, M.; Said, A. A.; Wei, T.-H.; Hagan, D. J.; Van Stryland, E. W. Sensitive Measurement of Optical Nonlinearities Using a Single Beam. IEEE J. Quantum Electron. 1990, 26, 760-769.

2. Ajami, A.; Husinsky, W.; Liska, R.; Pucher, N. Two-Photon Absorption Cross Section Measurements of Various Two-Photon Initiators for Ultrashort Laser Radiation Applying the Z-Scan Technique. J. Opt. Soc. Am. B 2010, 27, 2290-2297.

3. Ryan, E. T.; Xiang, T.; Johnston, K. P.; Fox, M. A. Absorption and Fluorescence Studies of Acridine in Subcritical and Supercritical Water. J. Phys. Chem. A 1997, 101, 1827-1835.

4. Mandal, S.; Ghatak, C.; Rao, V. G.; Ghosh, S.; Sarkar, N. Pluronic Micellar Aggregates Loaded with Gold Nanoparticles (Au NPs) and Fluorescent Dyes: A Study of Controlled Nanometal Surface Energy Transfer. J. Phys. Chem. C. 2012, 116, 5585-5597.

5. Jana, A.; Saha, B.; Ikbal, M.; Ghosh, S. K.; Singh, N. D. P. 1-(Hydroxyacetyl)pyrene a new fluorescent phototrigger for cell imaging and caging of alcohols, phenol and adenosine. Photochem. Photobiol. Sci. 2012, 11, 1558-1566.

6. Borman, C.; Sullivan, B. P.; Eggleston, C.; Colberg, P. The Use of Flow-Injection Analysis with Chemiluminescence Detection of Aqueous Ferrous Iron in Waters Containing High Concentrations of Organic Compounds. Sensors 2009, 9, 4390-4406.

7. Barman, S.; Mukhopadhyay, S. K.; Biswas, S.; Nandi, S.; Gangopadhyay, M.; Dey, S.; Anoop, A.; Pradeep Singh, N. D. A p-Hydroxyphenacyl-Benzothiazole-Chlorambucil Conjugate as a Real-TimeMonitoring Drug-Delivery System Assisted by ExcitedState Intramolecular Proton Transfer. Angew. Chem. Int. Ed. 2016, 55, 4194-4198.

8. Demas, J. N.; Bowman, W. D.; Zalewski, E. F.; Velapoldi, R. A. Determination of the quantum yield of the ferrioxalate actinometer with electrically calibrated radiometers. J. Phys. Chem.1981, 85, 2766-2771.

9. (a) Jana, A.; Atta, S.; Sarkar, S. K.; Singh, N. D. P. 1-Acetylpyrene with Dual Functions as an Environment-Sensitive Fluorophore and Fluorescent Photoremovable Protecting Group. Tetrahedron, 2010, 66, 9798-9807. (b) Klíčová, Ĺ.; Šebej, P.; Šolomek, T.; Hellrung, B.; Slavíček, P.; Klán, P.; Heger, D.; Wirz, J. Adiabatic Triplet State Tautomerization of PHydroxyacetophenone in Aqueous Solution. J. Phys. Chem. A, 2012, 116, 2935-2944. 